\title{
ON THE FUNDAMENTALS OF SELF-FULFILLING SPECULATIVE ATTACKS
}

\author{
Craig Burnside \\ Martin Eichenbaum \\ Sergio Rebelo \\ Working Paper 7554 \\ http://www.nber.org/papers/w7554 \\ NATIONAL BUREAU OF ECONOMIC RESEARCH \\ 1050 Massachusetts Avenue \\ Cambridge, MA 02138 \\ February 2000
}

\begin{abstract}
We are grateful to Kellogg's Banking Research Center for financial support. This project was started while Burnside was a National Fellow at the Hoover Institution which he thanks for its support. The opinions in this paper are those of the authors and not necessarily those of the Federal Reserve Bank of Chicago, the World Bank or the National Bureau of Economic Research. We are thankful to Larry Christiano and Olivier Jeanne for their comments.
\end{abstract}

(C) 2000 by Craig Burnside, Martin Eichenbaum and Sergio Rebelo. All rights reserved. Short sections of text, not to exceed two paragraphs, may be quoted without explicit permission provided that full credit, including (C) notice, is given to the source. 
On the Fundamentals of Self-Fulfilling Speculative Attacks

Craig Burnside, Martin Eichenbaum, and Sergio Rebelo

NBER Working Paper No. 7554

February 2000

JEL No. F31, F41, G15, G21

\section{ABSTRACT}

This paper proposes a theory of twin banking-currency crises in which both fundamentals and self-fulfilling beliefs play crucial roles. Fundamentals determine whether crises will occur. Selffulfilling beliefs determine when they occur. The fundamental that causes 'twin crises' is government guarantees to domestic banks' foreign creditors. When these guarantees are in place twin crises inevitably occur, but their timing is a multiple equilibrium phenomenon that depends on agents' beliefs. So while self-fulfilling beliefs have an important role to play, twin crises do not happen just anywhere. They happen in countries where there are fundamental problems - problems such as guarantees to the financial sector.

Craig Burnside

The World Bank

1818 H. Street, N.W.

Washington, D.C. 20433

Sergio T. Rebelo

J.L. Kellogg Graduate School of Management

Northwestern University

Leverone Hall

Evanston, IL 60208-2001

and NBER

s-rebelo@nwu.edu
Martin Eichenbaum

Department of Economics

Northwestern University 2003 Sheridan Road

Evanston, IL 60208

and NBER

eich@nwu.edu 


\section{Introduction}

The past decade has witnessed dramatic collapses of fixed exchange rate regimes in countries as diverse as Sweden, Mexico, Thailand and Korea. This has led to a resurgence of interest in the causes of currency crises. While there is disagreement about the source of these crises, there is widespread agreement that banking crises have become increasingly linked to currency crises. This is the 'twin crises' phenomenon emphasized by Kaminsky and Reinhart (1999).

This paper proposes a theory of such crises in which both fundamentals and self-fulfilling beliefs play crucial roles. ${ }^{1}$ Fundamentals determine whether crises will occur. Self-fulfilling beliefs determine when they occur. ${ }^{2}$ The fundamental that causes 'twin crises' is government guarantees to domestic banks' foreign creditors. When these guarantees are in place twin crises inevitably occur. But their timing is a multiple equilibrium phenomenon that depends on agents' beliefs. So while self-fulfilling beliefs have an important role to play, twin crises do not happen just anywhere. They happen in countries where there are fundamental problems, countries such as Sweden, Mexico, Thailand, and Korea.

In our model the government guarantees the repayment of bank's foreign loans in the event of a devaluation. These guarantees lead banks to expose themselves to exchange rate risk and to declare bankruptcy when a devaluation occurs. Consequently, a devaluation transforms potential government liabilities into actual liabilities. This transformation is the key mechanism by which government guar-

\footnotetext{
${ }^{1}$ The recent literature emphasizes the distinction between fundamental and multiple equilibrium explanations of 'twin crises.' For examples of papers that emphasize fundamentals see Corsetti, Pesenti and Roubini (1997), Bordo and Schwartz (1998), and Burnside, Eichenbaum and Rebelo (1998). For papers that stress the importance of multiple equilibrium considerations see, for example, Chang and Velasco (1997), Aghion, Bacchetta, and Banerjee (1999) and Krugman (1999).

${ }^{2}$ See Cole and Kehoe (1996) for a theory of debt crises in which both fundamentals and self-fulfilling beliefs play an important role.
} 
antees create the possibility of self-fulfilling currency crises. To understand our basic argument, assume that there is a limit on the amount of reserves that the government is willing to lose in defense of its currency. Now suppose that market participants believe that a devaluation is imminent and that the government will finance bank bailouts, at least in part, via seignorage revenues. Then private agents will exchange domestic money for foreign reserves to the point where the fixed exchange rate regime is abandoned. The resulting devaluation leads banks to declare bankruptcy and activates the government's obligations to foreign creditors. As a consequence, the government will validate agents' expectations by partially financing the bailout with seignorage revenues. Thus government guarantees trigger a self-fulfilling, rational run on the domestic currency, a devaluation and a banking crisis. Paradoxically, government guarantees make banks and the economy less stable, not more stable.

How can the government prevent these self-fulfilling twin crises? The two most obvious routes are: eliminate government guarantees or (somehow) credibly commit to financing post-devaluation bank bailouts without recourse to seignorage revenues. Our analysis suggests a third route related to a recent proposal by Feldstein (1999): the government must obtain and be willing to use a 'sufficient' amount of reserves to fend off a speculative attack. But what does 'sufficient' mean? In our model it means a fraction of the money supply that is an increasing function of the inflation rate that would result if a speculative attack succeeded. Finally, we analyze a fourth possibility: imposing a state contingent Tobin tax on exchange rate transactions.

The remainder of this paper is organized as follows. Section 2 presents a model of a small open economy which is populated by four different sets of agents: banks, firms, households, and a government. The banking sector is a simplified version of the one in Burnside, Eichenbaum and Rebelo (1999). Banks borrow dollars 
from abroad and make loans to domestic firms. By assumption these domestic loans are denominated in local currency, so that banks face foreign exchange rate risk. This risk can be hedged in forward currency markets. We characterize banks' optimal hedging strategy when the government guarantees that foreign creditors will be repaid in the event of a devaluation. In addition we consider the case in which these guarantees are absent. Firms borrow funds to hire labor and produce output using a constant returns to scale technology. Households supply labor inelastically and derive utility from consumption and domestic real balances. Because they have access to international capital markets they have a non-trivial forward looking portfolio problem. In particular, the amount of domestic real balances that they hold depends on their beliefs about the longevity of the fixed exchange rate regime. The government faces an intertemporal budget constraint which must hold for every realization of the state of the economy. To simplify the analysis we assume, as in Krugman (1979), that the government follows a threshold rule according to which it abandons fixed exchange rates when its reserves reach a certain lower bound.

The only source of uncertainty in this economy is agents' beliefs about the collapse of the fixed exchange rate regime. We model these beliefs by assuming that agents coordinate on an exogenous signal which takes on the value one with probability $q$ and zero with probability $(1-q)$. When the signal equals one agents believe that the exchange rate regime will collapse before the end of the period. When it equals zero, they believe that the fixed exchange rate will persist for at least one more period.

Section 3 displays the competitive equilibrium when self-fulfilling speculative attacks are ruled out by assumption. Section 4 analyzes the conditions under which these attacks can occur. Section 5 contains concluding remarks. 


\section{The Basic Model}

We consider a simple general equilibrium model of a small open economy. By assumption there is a single consumption good and no barriers to trade, so that purchasing power parity holds:

$$
P_{t}=S_{t} P_{t}^{*}
$$

Here $P_{t}$ and $P_{t}^{*}$ denote the domestic and foreign price level respectively, while $S_{t}$ denotes the exchange rate defined as units of domestic currency per unit of foreign currency. For convenience we normalize the foreign price level to one: $P_{t}^{*}=1$ for all $t$.

The economy is initially in a fixed exchange rate regime with $S_{t}=S^{I}$. To allow for the possibility of a self-fulfilling speculative attack, we suppose that agents coordinate on some signal, observed at the beginning of each period. The signal takes on the values zero or one with probabilities $1-q$ and $q$, respectively. When the signal is equal to zero, agents believe that the fixed exchange rate will endure for at least one more period. If the signal equals one, then agents believe the fixed exchange rate regime will collapse before the end of the period, with the exchange rate initially depreciating to an endogenously determined value $S^{D}$ and then depreciating at the rate $\gamma$ per unit of time.

The key question is whether agents' beliefs about a devaluation can be selffulfilling. We denote by $T$ the random time of a (possible) self-fulfilling speculative attack. It is useful to distinguish between three types of time periods in the life of our model economy.

- Fixed Exchange Rate Regime: here $S_{t}=S^{I}$ for all $t<T$ and the supply of money is determined by the central bank's need to fix the nominal exchange rate. 
- Devaluation Period: this is the time period $T$ in which the fixed exchange rate is abandoned. To simplify our analysis, we adopt the standard assumption of the speculative attack literature regarding the behavior of the monetary authority. ${ }^{3}$ Specifically, we assume that the central bank defends the fixed exchange rate $S^{I}$ by selling its reserves at that price until reserves fall by an amount $\chi$. Once this happens, the central bank floats the exchange rate, and allows the money supply to grow at the rate $\gamma$ forever.

- Floating Exchange Rate Regime: this obtains for all $t>T$. The growth rate of money is equal to $\gamma$. We consider two separate cases. In the first case the government does not change its tax and spending policy in the aftermath of the devaluation. Here $\gamma$ is endogenously determined by the magnitude of the bank bailout and the government's intertemporal budget constraint. In the second case $\gamma$ is given exogenously and taxes adjust so that the government's intertemporal budget constraint holds.

The economy is populated by four sets of agents: perfectly competitive banks, good producing firms, households, and a government. In the following subsection we provide a detailed analysis of the banking sector. We then discuss the problems of the other agents in the economy.

\subsection{The Banking Sector}

In this subsection we analyze a simplified version of the banking model in Burnside, Eichenbaum and Rebelo (1999) in which banks are exposed to exchange rate risk. The focus of our analysis is on banks' optimal hedging strategies when the economy is operating under the fixed exchange rate regime discussed above, i.e. at time $t<T$. We show that: (i) it is optimal for a bank to fully hedge exchange

\footnotetext{
${ }^{3}$ See, for example, Krugman (1979) and Flood and Garber (1984).
} 
rate risk when there are no government guarantees to foreign creditors; and (ii) it is not optimal for a bank to hedge exchange rate risk in the presence of government guarantees. In the latter case, it is optimal for banks to declare bankruptcy when the currency is devalued. The optimal hedging strategy has the property that when a bank declares bankruptcy, its residual value, net of bankruptcy costs is zero.

We assume that banks are perfectly competitive and their actions are publicly observable. Individual banks borrow foreign currency at a gross interest rate $R^{b}$, and issue non-indexed loans to domestic firms. These loans to firms are to be repaid in local currency units at a gross interest rate $R^{a}$. When firms repay these loans, the exchange rate $S$ is either $S^{I}$ or $S^{D}$, depending on whether the fixed exchange rate regime has been abandoned.

To simplify the analysis we assume that banks do not borrow funds from domestic residents. Instead banks finance themselves entirely by borrowing $L$ dollars in the international capital market. These funds are converted into units of local currency at the prevailing exchange rate, $S^{I}$. Banks can hedge exchange rate risk by entering into forward contracts. Let $F$ denote the one-period forward exchange rate defined as units of local currency per dollar. By assumption these contracts are priced in a risk neutral manner, so that:

$$
\frac{1}{F}=(1-q) \frac{1}{S^{I}}+q \frac{1}{S^{D}} .
$$

This condition states that the expected real rate of return of purchasing a forward contract, denominated in units of the consumption good, is equal to zero. Relation (2.2) implies that forward contracts make a profit in the devaluation state since $S^{D}>S^{I}$. To lend $L$ dollars, banks must incur transactions costs of $\delta L$. Dollardenominated profits from these loans are: 


$$
\pi^{L}\left(S, R^{b}\right)=\frac{R^{a} S^{I} L}{S}-R^{b} L-\delta L
$$

Dollar-denominated profits from hedging activities are given by:

$$
\pi^{H}(S)=x\left(\frac{1}{F}-\frac{1}{S}\right) .
$$

Here $x$ denotes the number of units of local currency sold by the bank in the forward market. We assume that there is full information about the values of $L$ and $x$ chosen by the banks. Notice that the expected value of the bank's profits from hedging is $E\left(\pi^{H}\right)=0$. Total dollar-denominated profits, $\pi$, are given by

$$
\pi(S)=\pi^{L}(S)+\pi^{H}(S)
$$

Banks can default on loans contracted in the international capital market. It is optimal for banks to default in states of the world where $\pi$ is negative. The expected profit of a bank that defaults whenever $\pi(S)<0$ is

$$
V=(1-q) \max \left\{\pi\left(S^{I}\right), 0\right\}+q \max \left\{\pi\left(S^{D}\right), 0\right\}
$$

When a bank defaults it has gross assets with a residual value given by

$$
V^{R}(S)=\frac{R^{a} S^{I} L}{S}-\delta L+x\left(\frac{1}{F}-\frac{1}{S}\right) .
$$

These assets, net of bankruptcy costs, are distributed to the bank's international creditors. We assume that bankruptcy costs are given by $\omega L$, where $\omega>0$.

In the Appendix we show that the bank's expected profit can be expressed as:

$$
V=\left(\frac{S^{I}}{F} R^{a}-\delta\right) L-E C B(x, L)
$$

where $E C B$, the expected cost of borrowing, is given by,

$$
E C B(x, L)=\operatorname{Pr}(\text { no default }) \times R^{b} L+\operatorname{Pr}(\text { default }) \times V^{R}
$$


Notice that in equation (2.7) $x$ only affects $\operatorname{ECB}(x, L)$. So for any given $L$, it is optimal for a bank to choose $x$ in order to minimize $E C B(x, L)$.

We consider two scenarios. In the first scenario there are no government guarantees to foreign creditors. If banks default foreign creditors receive the residual value of the bank net of bankruptcy costs, $V^{R}-\omega L$. We assume that there is no default on forward contracts-these contracts must be settled before the bank's foreign creditors are paid. This implies that if the bank defaults, its residual value must be sufficiently large to pay its bankruptcy costs: $V^{R}(S) \geq \omega L$ for all $(x, L)$ such that $V^{R}(S)<R^{b} L$. Using (2.6) this condition can be written as

$$
\frac{R^{a} S^{I} L}{S}-\delta L+x\left(\frac{1}{F}-\frac{1}{S}\right) \geq \omega L .
$$

For a given value of $L$, this imposes finite upper and lower bounds on the value of $x$ that an individual bank can choose.

In the second scenario the government guarantees foreign creditors against default by domestic banks, up to a repayment limit of $R L$. Here $R$ denotes the exogenously given risk free interest rate in international capital markets. No default on forward contracts continues to require $V^{R}(S) \geq \omega L$.

\section{No Government Guarantees}

Absent government guarantees, $R^{b}$ is determined by the condition that the expected return to international creditors equals $R$ :

$$
R L=\operatorname{Pr}(\text { no default }) \times R^{b} L+\operatorname{Pr}(\text { default }) \times\left(V^{R}-\omega L\right)
$$

Proposition 1 In an economy with no guarantees and $\omega>0$, it is optimal for banks to fully hedge exchange rate risk. When $\omega=0$, the Modigliani-Miller theorem applies and the bank is indifferent between hedging and not hedging. Proof: See the Appendix. 
To see the basic intuition behind this proposition note that using (2.8), we can write (2.10) as:

$$
R L=E C B(x, L)-\operatorname{Pr}(\text { default }) \times \omega L,
$$

so that

$$
E C B(x, L)=R L+\operatorname{Pr}(\text { default }) \times \omega L .
$$

The bank can avoid paying bankruptcy costs by choosing $x$ so that $\pi(S) \geq 0$ for all $S$. This strategy is optimal because it minimizes $\operatorname{ECB}(x, L)$. This establishes that full hedging is optimal for a bank in the absence of government guarantees, so that banks never go bankrupt.

For future reference it is useful to note that given a full hedging strategy, the bank's first order condition for $L$ is:

$$
\frac{R^{a} S^{I}}{F}=R+\delta
$$

This expression equates the expected real return to lending to the real cost of borrowing $(R)$ plus the marginal cost of producing a loan $(\delta)$.

\section{Government Guarantees}

In the presence of government guarantees $R^{b}$ is given by:

$$
\begin{gathered}
R L=\operatorname{Pr}(\text { no default }) \times R^{b} L+\operatorname{Pr}\left(\text { default when } S=S^{I}\right) \times\left(V^{R}-\omega L\right)+ \\
\operatorname{Pr}\left(\text { default when } S=S^{D}\right) \times \max \left\{V^{R}-\omega L, R L\right\}
\end{gathered}
$$

Proposition 2 Consider an economy in which the government guarantees the repayment of bank's foreign loans in the event of a devaluation. Suppose that $\omega<R$. Then fully hedging is not optimal and the optimal strategy is to set $x$ to its lowest permissible value.

Proof: See the Appendix. 
The intuition underlying Proposition 2 can be seen as follows. A bank whose $(x, L)$ is such that it defaults only in the devaluation state $\left(S=S^{D}\right)$, can borrow at the risk free rate: $R^{b}=R$. This fact and (2.8) imply that

$$
E C B(x, L)=(1-q) R L+q V^{R}\left(S^{D}\right) .
$$

Consider a bank that decided to default in the devaluation state. Its optimal strategy is to choose $x$ to minimize $\operatorname{ECB}(x, L)$, defined in (2.13). This requires setting $x$ to its lowest feasible value: $V^{R}\left(S^{D}\right)=\omega L$. It follows that when the bank pursues this strategy,

$$
E C B(x, L)=(1-q) R L+q \omega L .
$$

In contrast, suppose that the bank chooses a hedging strategy such that it is never optimal to default. Then $R^{b}=R$, and

$$
E C B(x, L)=R L
$$

It immediately follows that, as long as $q$ is positive and $\omega<R$, the optimal strategy for a bank is the first one, namely set $x$ to its lowest feasible bound and default whenever the devaluation state occurs. Following an argument similar to that used in the proof of Proposition 1, one can show that it is not optimal to default in the no-devaluation state, since government guarantees do not apply in that state.

Note that the optimal value of $x$ can be negative, so that banks make hedging profits during the fixed exchange regime and lose money when the currency is devalued. It is the latter feature that allows them to minimize their residual value in bankruptcy states, so that $V^{R}\left(S^{D}\right)=\omega L$. As a consequence, there are no assets, after bankruptcy costs, for the government to seize in order to offset their liabilities to banks' foreign creditors. 
It is useful to note, for future reference, that given the bank's optimal hedging strategy when there are government guarantees, its first order condition for $L$ is:

$$
\frac{R^{a} S^{I}}{F}=(1-q) R+\delta+q \omega .
$$

This expression equates the expected real return to lending to the real cost of borrowing plus the marginal cost of producing a loan. The term $q \omega$ reflects the fact that the bank pays bankruptcy costs, proportional to is total lending, with probability $q$.

\subsection{The Firm's Problem}

Output $(y)$ is produced by perfectly competitive firms which use labor $(h)$ according to the technology $y=A h$. Firms pay the real wage rate $w$, which is set at the beginning of the period, prior to the realization of the exchange rate. Wage payments are in units of the local currency. ${ }^{4}$ Firms must borrow their wage bill from the banks at the gross interest rate $R^{a}$, so their expected profits are given by $A h-R^{a} w h$. The first order condition for $h$ is:

$$
w=A / R^{a} .
$$

\subsection{The Household Problem}

The representative household inelastically supplies one unit of labor in each period and maximizes expected lifetime utility, which depends on consumption $\left(c_{t}\right)$ and real balances $\left(M_{t} / S_{t}\right)$ :

$$
\text { . } \quad U=E_{0} \sum_{t=0}^{\infty} \beta^{t}\left[\log c_{t}+\phi \log \left(M_{t} / S_{t}\right)\right], \quad 0<\beta<1 .
$$

\footnotetext{
${ }^{4}$ Firms must hedge against the risk of a devaluation to ensure that they can pay the agreed upon real wage rate. The details of the required hedging strategy are discussed in the Appendix.
} 
To abstract from trends in the economy's current account we assume that $\beta=$ $R^{-1}$. The sequential budget constraint faced by the household depends on the time period under consideration. During floating exchange rate periods $(t>T)$ it is given by:

$$
a_{t+1}=R a_{t}+w_{t}+\pi_{t}-\tau-c_{t}-\left(M_{t+1}-M_{t}\right) / S_{t} .
$$

The variable $a_{t}$ represents beginning of period $t$ net foreign assets, $M_{t}$ represents beginning of period $t$ nominal money balances, $w_{t}$ is real labor income, $\tau$ represents constant lump-sum taxes, and $\pi_{t}$ are the firm's profits. ${ }^{5}$

In the devaluation period $(t=T)$ the household's sequential budget constraint is given by:

$$
\begin{gathered}
a_{T+1}=R a_{T}+w_{T}+\pi_{T}-\tau-c_{T}-\frac{M_{T+1}-M^{D}}{S^{D}}+\chi+x_{T}^{h}\left(\frac{1}{F}-\frac{1}{S^{D}}\right), \\
M^{D}=M_{T}-\chi S^{I} .
\end{gathered}
$$

At the time of the devaluation the household redeems $\chi S^{I}$ units of local currency in exchange for foreign reserves. This is why its initial money holdings in (2.18) equal $M^{D}$, defined in (2.19), and the term $\chi$ appears as an asset. The variable $x_{T}^{h}$ denotes the number of units of local currency sold by the household in the forward market in the previous period. The household has an incentive to enter these contracts during the fixed exchange rate regime. By entering the forward market it can insure against the effect of a devaluation on the value of its real balances. We will see later that allowing households to hedge implies that consumption is constant over time. This greatly simplifies the analysis, enabling us to characterize analytically the equilibrium of the economy.

During the fixed exchange regime $(t<T)$ the budget constraint is:

$$
a_{t+1}=R a_{t}+w_{t}+\pi_{t}-\tau-c_{t}-\frac{M_{t+1}-M_{t}}{S^{I}}+x_{t}^{h}\left(\frac{1}{F}-\frac{1}{S^{I}}\right),
$$

\footnotetext{
${ }^{5}$ We ignore the profits of banks since bank profits are always zero in equilibrium.
} 
where $a_{0}$ and $M_{0}$ are given.

Finally we impose the no-Ponzi game condition: $E_{0} \lim _{t \rightarrow \infty} a_{t+1} / R^{t}=0$.

\subsection{The Government}

During the fixed exchange rate regime $(t<T)$ the government's flow budget constraint is:

$$
f_{t+1}=R f_{t}+\left(M_{t+1}^{S}-M_{t}^{S}\right) / S^{I}+\tau-g .
$$

Here $f_{t}$ denotes the government's net foreign assets at the beginning of the time period, $g$ is the constant level of real government purchases and $M_{t}^{S}$ denotes the endogenous level of the money supply that is consistent with a fixed exchange rate regime at time $t$. Not surprisingly, $M_{t}^{S}$ is constant for $t<T$.

The government's flow budget constraint during the devaluation period $(t=T)$ is:

$$
f_{T+1}=R f_{T}-\chi-\Gamma+\left(M_{T+1}^{S}-M^{D}\right) / S^{D}+\tau-g,
$$

Here, $\Gamma$ represents the cost of honoring guarantees to bank's foreign creditors. From Proposition 2 we know that $\Gamma=R L$. To simplify, we assume that the government repays $\Gamma$ in the devaluation period $T$.

During the floating exchange rate period the government's flow budget constraint is:

$$
f_{t+1}=R f_{t}+\left(M_{t+1}^{S}-M_{t}^{S}\right) / S_{t}+\tau-g .
$$

We impose the condition:

$$
E_{0} \lim _{t \rightarrow \infty} f_{t+1} / R^{t}=0 .
$$

Note that once the fixed exchange rate is abandoned, there is no uncertainty in the economy. This fact together with equations (2.22), (2.23) and (2.24) imply 
that at time $T$ the government's intertemporal budget constraint is:

$$
\Gamma+\chi=\frac{M_{T+1}^{S}-M^{D}}{S^{D}}+\sum_{j=1}^{\infty} \frac{1}{R^{j}}\left(\frac{M_{T+j+1}^{S}-M_{T+j}^{S}}{S_{T+j}}\right) .
$$

This equation simply says that seignorage revenues must equal the value of the bailout, $\Gamma$, plus the loss of reserves incurred during the attack.

\subsection{The Competitive Equilibrium}

We conclude this section with a definition of the competitive equilibrium that applies to economies with and without government guarantees to foreign creditors. Definition A competitive equilibrium for this economy is a set of stochastic processes for quantities $\left\{c_{t}, x_{t}, x_{t}^{h}, M_{t}, M_{t}^{S}, a_{t+1}, f_{t+1}, \Gamma, h_{t}, L_{t}\right\}$ and prices $\left\{w_{t}, R_{t}^{a}, R_{t}^{b}\right.$, $\left.P_{t}, S_{t}, F_{t}\right\}$ such that: (i) $c_{t}, x_{t}^{h}, M_{t+1}, a_{t+1}$ solve the household's problem given the stochastic process for prices; (ii) the government's intertemporal budget constraint (2.21) - (2.25) holds; (iii) the money market clears with $M_{t}^{S}=M_{t}$; (iv) the loan market clears with $L_{t}=w_{t} h_{t}$; and $(v)$ the labor market clears with $h_{t}=1$.

\section{A Sustainable Fixed Exchange Rate Regime}

In this section we describe a version of our economy in which self-fulfilling currency attacks are ruled out by assumption. The purpose is to demonstrate that there exists a sustainable equilibrium with a fixed exchange rate. The existence of this equilibrium follows from two basic assumptions: (i) agents assign probability zero to a devaluation, so that there is no uncertainty in the economy; (ii) the government does not require seignorage revenues to satisfy its intertemporal budget constraint.

Since there is no exchange rate uncertainty banks can borrow from foreigners at the risk free rate, $R^{b}=R$. Absent the possibility of a devaluation, government 
guarantees are irrelevant, so that $\Gamma=0$. Also, hedging plays no role in the analysis, so $x_{t}=x_{t}^{h}=0$. Finally, the forward rate coincides with the spot rate $F=S^{I}$.

It follows from (2.11) that:

$$
R^{a}=R+\delta
$$

In addition, equation (2.15) implies that the market clearing real wage rate is given by:

$$
w=A /(R+\delta)
$$

This completes the description of the equilibrium prices.

To determine the household's consumption and real balances we write its value function as:

$$
V\left(a_{t}, M_{t}\right)=\max _{c_{t}, a_{t+1}, M_{t+1}}\left\{\log c_{t}+\phi \log \left(M_{t} / S^{I}\right)+\beta V\left(a_{t+1}, M_{t+1}\right)\right\}
$$

subject to (2.17). The first order conditions for this problem are:

$$
\begin{aligned}
1 / c_{t} & =\beta\left(\frac{1}{c_{t+1}}+\frac{\phi}{M_{t+1} / S^{I}}\right), \\
1 / c_{t} & =\beta R / c_{t+1} .
\end{aligned}
$$

Our assumption that $\beta=R^{-1}$ implies that consumption and money holdings are constant over time. Using this fact, iterating on (2.17) and imposing the transversality condition $\lim _{t \rightarrow \infty} \beta^{t} a_{t+1} / c_{t+1}=0$, we obtain that net foreign assets are constant over time. In addition we find that:

$$
\begin{aligned}
c_{t} & =(R-1) a_{0}+w-\tau, \\
a_{t} & =a_{0}, \\
m_{t} & =M / S^{I}=\beta \phi c /(1-\beta) .
\end{aligned}
$$


Here we have used the fact that firms' profits are zero in equilibrium.

Since real balances are constant and the inflation rate is zero, the government collects no seignorage revenues. Consequently, its intertemporal budget constraint is given by:

$$
(R-1) f_{0}=g-\tau .
$$

By construction, this analysis demonstrates that there is a unique fixed exchange rate competitive equilibrium with $c_{t}, a_{t}$ and $M_{t}$ constant over time, given by (3.1)(3.3). In addition $f_{t}$ is constant: $f_{t}=f_{0}$. This completes the description of the equilibrium quantities.

Throughout the paper we assume that (3.4) holds, so that, in the absence of self-fulfilling speculative attacks, the fixed exchange rate regime is sustainable.

Combining the government and household budget constraints and using the fact that $c_{t}, a_{t}, f_{t}$ and $M_{t}$ are constant over time, we can express the economy's aggregate resource constraint as

$$
c+g=(R-1)\left(a_{0}+f_{0}\right)-A \frac{R+\delta-1}{R+\delta}+A .
$$

Notice that the first term on the right hand side is net interest on foreign assets. The second term is the real cost of intermediation. The latter reflects the physical costs of producing loans and the interest rate costs incurred because domestic banks borrow funds from abroad. ${ }^{6}$ Since employment is normalized to 1 , total output, the last term, is equal to $A$.

\footnotetext{
${ }^{6}$ Banks borrow $w=A /(R+\delta)$ dollars abroad. They use $\delta A /(R+\delta)$ units of output to produce these loans. At the end of the period they repay foreigners at a net cost of $(R-1) A /(R+\delta)$. Thus, the total cost of intermediation is $(R+\delta-1) A /(R+\delta)$.
} 


\section{Self-Fulfilling Currency Attacks}

In this section we turn to the question: Can self-fulfilling speculative attacks occur in an economy with government guarantees? To answer this question we begin by assuming that such an attack can exist. We then construct candidate equilibrium price and quantity allocations for the three types of time periods in our model. By construction these allocations satisfy the optimization problems of the different agents in the model and the market clearing conditions. The key condition that must be verified is whether $S^{D} / S^{I}>1$, i.e. the exchange rate actually devalues in the proposed equilibrium. Whether or not this is true depends on the nature of monetary and fiscal policy after the devaluation. Here we consider two cases. First, we analyze the 'no fiscal reform' case. Here the government finances the costs associated with a devaluation entirely via seignorage revenues. For the sake of simplicity we confine ourselves to an endogenously determined constant growth rate of money. Proposition 3 establishes that, subject to a regularity condition, self-fulfilling speculative attacks will occur. Second, we analyze the 'fiscal reform' case. Here the government commits to expanding the growth rate of money at an exogenous rate $\gamma$ and adjusts lump sum taxes to fulfill its intertemporal budget constraint. Proposition 4 provides conditions on the quantity of reserves that the government is prepared to lose, the growth rate of money, and the size of the bailout for which a self-fulfilling attack will occur.

We solve our model in three stages. First we study the floating exchange rate regime. Then, we analyze the fixed exchange rate regime. Finally, we consider the devaluation period. Below we summarize the key features of the economy during the different time periods, assuming that a self-fulfilling speculative attack exists.

Throughout our discussion wè use the fact, proved in the Appendix, that 
consumption, $c_{t}$, and the household's real assets $a_{t}$ are constant for all $t$ :

$$
c=(R-1)\left(a+f^{I}\right)-g+\frac{(R-1) w^{I}+q w^{F}-q(R-1) \Gamma}{R-1+q} .
$$

Here $w^{I}$ denotes the real wage rate during the fixed exchange rate period and the period in which the devaluation occurs, while $w^{F}$ denotes the real wage rate during the floating exchange rate period. The fact that $c_{t}$ and $a_{t}$ are constant hinges on our assumption that during the fixed exchange rate period households hedge exchange rate risk through forward contracts. According to (4.1), consumption is equal to the household's permanent income, where the latter is defined to take account of the annuitized expected present value of the bank bailout, $q(R-$ 1) $\Gamma /(R-1+q)$.

\subsection{The Floating Exchange Rate Regime $(t \geq T+1)$}

With no exchange rate uncertainty, banks can borrow from foreigners at the risk free rate, $R^{b}=R$. The presence of guarantees is irrelevant and hedging plays no role in the analysis, so $x_{t}=x_{t}^{h}=0$. Firms earn zero profits in each period. Finally, the forward rate coincides with the spot rate, so $F_{t}=S_{t+1}$ and $F_{t} / S_{t}=\gamma$. The law of motion for the exchange rate and the money supply are:

$$
\begin{aligned}
S_{t} & =S^{D} \gamma^{t-T}, t \geq T \\
M_{t} & =M^{D} \gamma^{t-T}, t \geq T
\end{aligned}
$$

Recall that $S^{D}$ is the exchange rate that prevails when the government abandons the fixed exchange rate in period $T$. The variable $M^{D}$ represents the level of the money supply after the speculative attack.

The banks' first order condition for $L$ during the floating exchange rate regime implies:

$$
R^{a}=\gamma(R+\delta)
$$


while equation (2.15) implies that the market clearing real wage rate is given by $w^{F}=A /[\gamma(R+\delta)]$.

During the floating exchange rate regime expected inflation is constant and equal to $\gamma-1$. The demand for real balances is given by:

$$
m^{F}=M_{t} / S_{t}=\phi c(\gamma / \beta-1)
$$

Relation (4.4) implies that real balances are a decreasing function of the nominal interest rate since the latter equals $\gamma / \beta-1$ during the flexible exchange rate regime.

\subsection{The Fixed Exchange Rate Regime $(t<T)$}

At any time period $t<T$ there is exchange rate uncertainty, since a devaluation may occur next period with probability $q$. In the presence of government guarantees banks behave as described in Proposition 2 and $R^{b}=R$. In addition, banks set $x_{t}$ to the lowest value consistent with (2.9). The exchange rate is equal to $S^{I}$ and the forward rate is given by (2.2). Denote the inflation rate between time $t$ and $t+1$ by $\pi_{t}$. Then, the time $t$ equilibrium interest rate at which banks lend to firms, given by (2.14), can be written as

$$
R^{a}=\frac{(1-q) R+\delta+q \omega}{E_{t}\left[1 /\left(1+\pi_{t}\right)\right]}
$$

where $E_{t}\left[1 /\left(1+\pi_{t}\right)\right]=(1-q)+q S^{I} / S^{D}$. The numerator of $(4.5)$ reflects the fact that the bank only pays off its loans if there is no devaluation, a state that occurs with probability $(1-q)$. If we were to make the approximation (which we don't) that $1 /\left\{E_{t}\left[1 /\left(1+\pi_{t}\right)\right]\right\} \cong E_{t}\left(1+\pi_{t}\right)$, then we would obtain a version of the Fisher equation for the nominal interest rate, $R_{a}=E_{t}\left(1+\pi_{t}\right)[(1-q) R+\delta+q \omega]$.

Real wages are given by the firm's first order condition, (2.15):

$$
w^{I}=A / R^{a} .
$$


In the Appendix we show that the solution to the household problem yields a constant value for $x_{t}^{h}$ which satisfies:

$w^{I}+\pi^{I}+x^{h}\left(\frac{1}{F}-\frac{1}{S^{I}}\right)=\left[w^{I}+\pi^{D}+x^{h}\left(\frac{1}{F}-\frac{1}{S^{D}}\right)\right] \frac{R-1}{R}-\frac{R-1}{R} \Gamma+\frac{1}{R} w^{F}$

The left hand side of (4.7) denotes the household's income in non-devaluation states. The term $x^{h}\left(1 / F-1 / S^{I}\right)$ is the loss associated with forward contracts in those states of the world. The first term on the right hand side is the annuity value of labor income, firm profits and forward contract profits in the devaluation period. The second term is the annuity value of the bailout. Finally, the third term is the constant wage rate in the floating exchange rate period (profits are equal to zero under floating exchange rates). By choosing this value of $x^{h}$ the household can perfectly smooth consumption across the devaluation and non-devaluation states of the world.

During the fixed exchange rate regime expected inflation is constant and equal to $q\left(S^{D} / S^{I}-1\right)$. In the Appendix we show that households choose real balances so that

$$
m^{I}=\frac{\phi c \beta}{1-\beta+\beta q\left(1-S^{I} / S^{D}\right)}
$$

Note that real balances are decreasing in expected inflation. During this regime the endogenous money supply must be consistent with the real balances demanded by households and the fixed exchange rate. Therefore $M_{t}^{S}=S^{I} m^{I}$ for all $t<T$.

\subsection{The Devaluation Period $(t=T)$}

At the beginning of period $T$, prior to the realization of the stochastic process signalling the onset of a devaluation, banks borrow from abroad and lend to domestic firms at the value of $R^{a}$ that prevails in the fixed exchange rate regime. Proposition 2 implies that, in an economy with government guarantees, once the currency 
is devalued the banks renege on their foreign debt and declare bankruptcy. Due to the banks' hedging strategy, their residual value, net of bankruptcy costs, is equal to zero. Thus the total realized liability of the government, $\Gamma$, is $R L$.

Since firms make their hiring decisions at the beginning of the period prior to the devaluation, the real wage is the same as in the fixed exchange rate regime and is given by (4.6).

Recall that households enter the period with $M_{T}=m^{I} S^{I}$ units of the local currency. Once the random variable signaling the onset of a devaluation is realized, agents redeem $\chi S^{I}$ units of local currency in exchange for foreign reserves. The exchange rate rises from $S^{I}$ to $S^{D}$, at which point agents are left holding $M^{D}=$ $M^{T}-\chi S^{I}$ units of local currency. In the Appendix we prove the following lemma which reflects our assumption that money grows at the rate $\gamma$ starting from the level $M^{D}$ (see equation 4.2).

Lemma The rate of inflation from the onset of the devaluation to the first period of the floating exchange rate regime $(T+1)$ is: $S_{T+1} / S^{D}=\gamma$. The level of real balances at the onset of the devaluation is:

$$
\frac{M^{D}}{S^{D}}=m^{F}=\frac{\phi c}{\gamma / \beta-1}
$$

Integrating over the previous results we have constructed all of the endogenous variables in an equilibrium where a self-fulfilling currency attack occurs at the random date $T$ as a function of three unknowns: $\gamma, S^{D}$ and $m^{I}$. We now solve for these three variables and verify whether $S^{D}$ exceeds $S^{I}$, i.e. whether a selffulfilling currency attack actually occurs at $T$.

\section{No Fiscal Reform}

We first consider the case in which there is no fiscal reform, i.e. the government finances all of the costs associated with a devaluation via seignorage revenues. 
Proposition 3 Suppose that in the event of a devaluation the government chooses $\gamma$ so that the present value of government liabilities after a devaluation, $\Gamma+\chi$, is fully financed by seignorage. Then, as long as $\Gamma>0$ and $\Gamma+\chi$ is smaller, for some $q>0$, than the maximum present value of seignorage, $\phi c_{S} /(R-1)$, a self-fulfilling speculative attack exists. Here $c_{S}$ denotes the level of consumption in the sustainable fixed exchange rate equilibrium, defined in (3.5).

Proof: See the Appendix.

The previous proposition implies that as long as there are government guarantees and it is feasible to finance the obligations associated with the devaluation via seignorage, a self-fulfilling speculative attack will almost surely occur. The basic intuition for this is that with government guarantees a devaluation transforms potential liabilities into actual liabilities. If forward looking agents believe that these liabilities are financed via seignorage, they will reduce their domestic money holdings, exchanging them for foreign reserves. Given our assumptions this triggers the government threshold rule for abandoning the fixed exchange rate regime. At this point, the banks declare bankruptcy, which forces the government to payoff foreign creditors. This, in turn, rationalizes the private agents' beliefs about monetary policy and inflation that generated the crisis to begin with.

Under the assumptions of Proposition 3, this is true regardless of the reserves that the government is willing to spend in defense of the currency, $\chi$. The reason for this is that the higher $\chi$ is, the higher are the government's losses during the speculative attack and the more seignorage that needs to be collected after the fixed exchange rate regime is abandoned.

To understand the regularity condition $\Gamma+\chi<\phi c_{S} /(R-1)$, the right hand side of this inequality equals the maximal present value of seignorage that the government can extract from the economy. Using (4.4) and (4.9) it is straightforward to show that, for a given value of $\gamma$, the present value of seignorage is given 
by $\phi c(\gamma-1) /[(\gamma-\beta)(R-1)]$. It follows that seignorage is strictly increasing in $\gamma$ with maximal value equal to $\phi c /(R-1)$ corresponding to $\gamma=\infty$. In the Appendix we show that $c_{S}$ is an upper bound on the equilibrium value of $c$ that is attained in the limit, for arbitrarily small $q$; hence the upper bound on seignorage is $\phi c_{S} /(R-1)$. In order for a self-fulfilling currency attack to occur in the 'no fiscal reform' case, it is necessary and sufficient that $\Gamma+\chi$ be smaller than the maximum present value of seignorage. The reason this condition is necessary is that agents are expecting that the costs associated with a devaluation, $\Gamma+\chi$, will be fully financed with seignorage. Obviously, if this is not possible, such an expectation cannot be self-fulfilling.

\section{Fiscal Reform}

We now turn to the case in which the devaluation is accompanied by a fiscal reform. Specifically, we assume that the law of motion for money is given by (4.4) where $\gamma$ is now an exogenous parameter. Since the government's intertemporal budget constraint does not hold for an arbitrary $\gamma$, we suppose that a devaluation is followed by a fiscal reform in which lump sum taxes are adjusted to ensure that the intertemporal budget constraint, (2.25), holds. The following proposition characterizes the necessary and sufficient conditions for a self-fulfilling currency attack to occur under these circumstances.

Proposition 4 Suppose that in the event of a devaluation the government finances the present value of government obligations associated with the devaluation, $\Gamma+\chi$, by choosing a fixed value of $\gamma$ and financing the remainder with post devaluation taxes, $\tau^{D}$. Then a self-fulfilling speculative attack exists if:

$$
\chi \leq m_{S} \frac{\gamma-1}{\gamma-\beta}
$$

where $m_{S}$, defined in (3.3), is the level of real balances in a sustainable fixed 
exchange rate regime $(q=0)$. The value of $\tau^{D}$ is given by:

$$
\tau^{D}=\chi+\Gamma-\phi c \frac{\beta}{\gamma-\beta} \frac{\gamma-1}{1-\beta}
$$

Proof: See the Appendix.

According to (4.10) the government must be able to buy more than a fraction $(\gamma-1) /(\gamma-\beta)$ of the real balances in a sustainable fixed exchange rate regime to avoid a self-fulfilling speculative attack. Note that if the government sets $\gamma$ to infinity the right hand side of (4.10) converges to $m_{S}$. So, in this case the government must be able to buy back all outstanding real balances to avoid a speculative attack. Finally, if the government can credibly commit to not using seignorage revenues to finance an eventual bank bailout (i.e. it sets $\gamma$ to one), then self-fulfilling speculative attacks do not exist. We elaborate on this point below.

\section{Policy Implications}

How can a government eliminate self-fulfilling currency attacks? Our model suggests four possibilities: (i) eliminate government guarantees; (ii) obtain a high enough level of reserves, that in combination with a credible partial fiscal reform will allow the government to successfully fend off a speculative attack; (iii) impose a tax on purchases of foreign currency in the event that a speculative attack occurs, and (iv) get someone else to pay for the bank bailouts. We discuss each of these in turn. 


\section{Eliminating Government Guarantees}

In practice there may be many reasons for governments to provide guarantees to banking systems. Propositions 3 and 4 make concrete one cost of doing this. These propositions show, under assumptions of our model, that absent these guarantees self-fulfilling currency attacks do not exist.

Proposition 5 Suppose that there are no government guarantees to bank's foreign creditors. In addition, suppose that agents believe that in the event of a devaluation taxes and government spending remain constant, while the growth rate of money, $\gamma$, is constant. Then, self-fulfilling speculative attacks do not exist. Proof: See the Appendix.

The basic idea used in our proof is that absent government guarantees $\Gamma=0$. So, if a self-fulfilling currency attack succeeded, the government's liabilities would increase only by $\chi$, which is the loss of reserves at the time of the attack. Since the government's intertemporal budget constraint held prior to the attack, this means that the value of seignorage revenues associated with a particular value of $\gamma$ would have to exactly equal $\chi$ in equilibrium. Under the assumptions of our model this is not possible unless $S^{I} / S^{D}=1$.

Proposition 5 does not rule out the existence of self-fulfilling speculative attacks for more complicated paths of the money supply after the devaluation, or different money demand formulations. ${ }^{7}$ Still, the proposition establishes the presumption that eliminating guarantees makes the possibility of self-fulfilling speculative attacks less likely.

\section{Reserves and Fiscal Reforms}

An implication of Proposition 4 is that a self-fulfilling attack can be avoided if the government credibly commits to raising taxes by the amount $\tau_{D}$ and is willing

\footnotetext{
${ }^{7}$ Results in Obstfeld (1986) suggest that such self-fulfilling attacks are possible.
} 
to spend an amount of reserves that exceeds $m_{S}(\gamma-1) /(\gamma-\beta)$. This formalizes a point stressed by Feldstein (1999) and others: having access and being able to use reserves to fend off a speculative attack, can eliminate the possibility of attacks. However, committing reserves is useful only if the government is also committed to an associated fiscal reform. In the limit, if the government can somehow credibly commit to completely paying its post devaluation liabilities with a fiscal reform, then the level of reserves is actually irrelevant. Under these circumstances, $\gamma=1$, the right hand side of (4.10) is zero and any positive amount of reserves forecloses the possibility of a self-fulfilling speculative attack.

\section{Tobin Taxes}

Recall that agents in our model coordinate on a signal that takes on the value one (which is associated with a devaluation) with probability $q$. Suppose that there are government guarantees but the government is not committed to a fiscal reform of the type described in Proposition 4. Instead, the government commits to taxing foreign exchange transactions at the rate $\theta$. So, if a successful attack occurs, the government will obtain tax revenues of $\theta \chi$. This revenue, together with seignorage revenues, must totally finance the liabilities associated with a devaluation.

This simple Tobin tax has two effects. First, it alleviates the need to use seignorage revenues to finance the liabilities associated with a devaluation. In the case where these revenues can finance the entire bank bailout $(\theta \chi \geq \Gamma)$, the Tobin tax amounts to a fiscal reform of such magnitude that seignorage revenues are not required to finance the costs associated with a devaluation. Thus, a devaluation does not occur. ${ }^{8}$ We view this condition as unlikely to ever hold in practice, since it would require either huge values of $\chi$ or prohibitive values for $\theta$.

\footnotetext{
${ }^{8}$ See the introduction to the proofs of Propositions $3-5$ in the Appendix.
} 
Second, the Tobin tax affects the incentives of private agents to trade local currency for foreign reserves. The after-tax profit to a private agent from converting a unit of local currency into reserves in the devaluation period is $\left(1-\theta-S^{I} / S^{D}\right)$. Obviously, if $\theta$ is such that $1-\theta-S^{I} / S^{D}<0$ agents will not attack the currency. The actual value of $\theta$ required to rule out a speculative attack depends on all the determinants of $S^{D}$, such as $\gamma$. For every $\gamma$ there exists an $S^{D}$, and therefore a $\theta$, that would rule out the attack. So in principle such a tax could be used to eliminate self-fulfilling currency attacks. But one obvious problem with the tax is its state contingent nature. Just what signal needs to be credibly observed to declare that a speculative attack is self-fulfilling in nature?

\section{An External Bailout}

A final strategy for eliminating self-fulfilling speculative attacks is to gain access to an external entity that covers the costs of a bailout, $\Gamma$, if a speculative attack ever occurs. This guarantees that the government does not have to collect seignorage revenues, thus eliminating the possibility of self-fulfilling speculative attacks. Since no attacks happen in equilibrium the lender of last resort never has to intervene. Even though this strategy works in the context of our model we are deeply skeptical about its real world applicability. In our model the only margin that banks can use to take advantage of the implicit government guarantees is to expose themselves to exchange rate risk. In practice banks can exploit the presence of guarantees using other margins (e.g. investing in risky real estate ventures). In the presence of these additional margins a lender of last resort would create the moral hazard problems discussed by Calomiris (1998), Chari and Kehoe (1998), Mishkin (1999) and others. 


\section{Conclusion}

This paper developed a theory of 'twin crises' in which both fundamentals and selffulfilling beliefs play an important role. The presence of government guarantees to banks' foreign creditors implies that a 'twin crisis' will inevitably occur. In this sense fundamentals matter. This makes us optimistic about the prospect of identifying countries in which crises will occur. However, the timing of the crises in our model depends subtly on agent's self-fulfilling beliefs about when the fixed exchange rate regime will collapse. This makes us pessimistic about the prospect of forecasting the precise time at which 'twin crises' will occur.

\section{References}

Aghion, Philippe, Philippe Bacchetta, and Abhijit Banerjee (1999) "A Simple Model of Monetary Policy and Currency Crises," Working Paper, Harvard University.

Bordo, Michael and Anna J. Schwartz (1998) "Under What Circumstances, Past and Present, Have International Rescues of Countries in Financial Distress Been Successful?" NBER Working Paper No. 6824.

Burnside, Craig, Martin Eichenbaum and Sergio Rebelo (1998) "Prospective Deficits and the Asian Currency Crisis," NBER Working Paper No. 6758, 1998.

Burnside, Craig, Martin Eichenbaum and Sergio Rebelo (1999). "Hedging and Financial Fragility in Fixed Exchange Rate Regimes," NBER Working Paper No. 7143 .

Calomiris, Charles (1998) "The IMF'S Imprudent Role as Lender of Last Resort," The Cato Journal, 17, 275-94.

Chang, Roberto and Andres Velasco (1997) "Financial Fragility and the Exchange Rate Regime," NBER Working Paper No. 6469.

Chari, V.V. and Patrick Kehoe (1998) "Asking the Right Questions About the IMF," Federal Reserve Bank of Minneapolis Annual Report, Special Issue, 13, 2-26. 
Cole, Harold and Timothy Kehoe (1996) "A Self-Fulfilling Model of Mexico's 1994-95 Debt Crisis," Journal of International Economics, 41, 309-30.

Corsetti, Giancarlo, Paolo Pesenti and Nouriel Roubini (1998) "Paper Tigers? A Model of the Asian Crisis," Working Paper, Yale University.

Feldstein, Martin (1999) "Self-Protection for Emerging Market Economies," NBER Working Paper No. 6907.

Flood, Robert and Peter Garber (1984) "Collapsing Exchange Rate Regimes: Some Linear Examples," Journal of International Economics, 17, 1-13.

Kaminsky, Graciela and Carmen Reinhart (1999) "The Twin Crises: The Causes of Banking and Balance-of-Payments Problems," American Economic Review, 89, 473-500.

Krugman, Paul (1979) "A Model of Balance of Payments Crises," Journal of Money, Credit and Banking, 11, 311-25.

Krugman, Paul (1999) "Analytical Afterthoughts on the Asian Currency Crisis," Working Paper, MIT.

Mishkin, Frederic (1999) "Global Financial Instability: Framework, Events, Issues," Journal of Economic Perspectives, 13, 3-20.

Obstfeld, Maurice (1986) "Rational and Self-Fulfilling Balance-of-Payments Crises," American Economic Review, 76, 72-81. 


\section{A. Appendix}

\section{A.1. The Banking Sector}

We first establish that under the fixed exchange rate regime the objective function of the representative bank, (2.5), can always be rewritten as

$$
V(x, L)=E\left(V^{R}\right)(L)-E C B(x, L)=\left(\frac{S^{I}}{F} R^{a}-\delta\right) L-E C B(x, L) .
$$

Informally, $\operatorname{ECB}(x, L)$ is given by (2.8). Formally, it is equal to

$$
E C B(x, L)=\sum_{s \in\left\{S^{I}, S^{D}\right\}} \operatorname{Pr}(S=s) \min \left\{R^{b} L, V^{R}(s)\right\}
$$

From (2.6) we get $V^{R}(S)=\pi(S)+R^{b} L$. It follows that from (2.5) we obtain

$$
V=(1-q) \max \left\{V^{R}\left(S^{I}\right)-R^{b} L, 0\right\}+q \max \left\{V^{R}\left(S^{D}\right)-R^{b} L, 0\right\} .
$$

Notice that $\max \left\{V^{R}(S)-R^{b} L, 0\right\}=V^{R}(S)-\min \left\{R^{b} L, V^{R}(S)\right\}$. So we have

$$
V=E\left(V^{R}\right)-(1-q) \min \left\{R^{b} L, V^{R}\left(S^{I}\right)\right\}-q \min \left\{R^{b} L, V^{R}\left(S^{D}\right)\right\} .
$$

In what follows it is convenient to divide the set of feasible $(x, L)$ pairs into 4 subsets:

1. $(x, L)$ pairs such that the bank is fully hedged, and never defaults,

2. $(x, L)$ pairs such that the bank defaults only when $S=S^{I}$,

3. $(x, L)$ pairs such that the bank defaults only when $S=S^{D}$, and

4. $(x, L)$ pairs such that the bank defaults in both states.

Proof of Proposition 1. We begin with the fact that (2.10) can be rewritten as

$$
R L=\sum_{s \in\left\{S^{I}, S^{D}\right\}} \operatorname{Pr}(S=s)\left\{\begin{array}{ll}
R^{b} L & \text { if } V^{R}(s) \geq R^{b} L \\
V^{R}(s)-\omega L & \text { otherwise }
\end{array}\right\}
$$

for strategies $1-3$, and $E\left(V^{R}\right)-\omega L \geq R L$, for strategy 4 . Hence

$$
E C B(x, L)=R L+\sum_{s \in\left\{S^{I}, S^{D}\right\}} \operatorname{Pr}(S=s)\left\{\begin{array}{ll}
0 & \text { if } V^{R}(s) \geq R^{b} L \\
\omega L & \text { otherwise }
\end{array}\right\}
$$


for strategies 1-3 and $E C B=E\left(V^{R}\right)$ for strategy 4. This implies that fullhedging, when feasible, strictly dominates strategies 2 and 3 , since $\omega L>0$. Fullhedging is feasible whenever $E\left(V^{R}\right) \geq R L$ or $R^{a} \geq\left(F / S^{I}\right)(R+\delta)$.

Suppose $R^{a}>\left(F / S^{I}\right)(R+\delta)$. This implies that full-hedging is feasible but also that banks could make infinite profits by lending infinite amounts.

On the other hand, if $R^{a}<\left(F / S^{I}\right)(R+\delta)$ then $E\left(V^{R}\right)<R L$ so that fullhedging and strategy 4 are not feasible. Strategies 2 and 3 imply $V<0$.

This implies that the only possible equilibrium interest rate is $R^{a}=\left(F / S^{I}\right)(R+$ $\delta)$. In this case full hedging is feasible at $x=F(R+\delta) L$ and $E\left(V^{R}\right)=R L$, implying $V=0$. As stated above, since full-hedging is feasible it strictly dominates strategies 2 and 3. Strategy 4 is not feasible since $E\left(V^{R}\right)=R L$.

Proof of Proposition 2. Under guarantees, if there is default when $S=S^{D}$, foreign creditors receive $\max \left\{V^{R}\left(S^{D}\right)-\omega L, R L\right\}$. Hence, for strategies 1-3, the condition determining a bank's borrowing rate when there are guarantees can be formally written as

$$
\begin{aligned}
R L=(1-q) & \times\left\{\begin{array}{ll}
R^{b} L & \text { if } V^{R}\left(S^{I}\right) \geq R^{b} L \\
V^{R}\left(S^{I}\right)-\omega L & \text { otherwise }
\end{array}\right\}+ \\
q & \times\left\{\begin{array}{ll}
R^{b} L & \text { if } V^{R}\left(S^{D}\right) \geq R^{b} L \\
\max \left\{V^{R}\left(S^{D}\right)-\omega L, R L\right\} & \text { otherwise }
\end{array}\right\} .
\end{aligned}
$$

A bank following strategy 4 faces the constraint that $(1-q)\left[V^{R}\left(S^{I}\right)-\omega L\right]+$ $q \max \left\{V^{R}\left(S^{D}\right)-\omega L, R L\right\} \geq R L$. It follows that

1. full-hedging implies that $R^{b}=R$ and $E C B=R L$,

2. strategy 2 implies that $R L=(1-q)\left[V^{R}\left(S^{I}\right)-\omega L\right]+q R^{b} L$ and $E C B=$ $R L+(1-q) \omega L$,

3. strategy 3 implies that $R^{b}=R$ and $E C B=(1-q) R L+q V^{R}\left(S^{D}\right),{ }^{9}$ and 4. strategy 4 implies that $E C B=E\left(V^{R}\right)$.

First, consider the possibility that the equilibrium interest rate is such that $R^{a}>\left(F / S^{I}\right)[(1-q) R+\delta+q \omega]$. It is easy to establish that in such circumstances, banks following strategy 3 would be able to make infinite profits by lending infinite amounts.

\footnotetext{
${ }^{9}$ Notice that under strategy $3, V^{R}\left(S^{D}\right)<R L$, since otherwise we would have $V^{R}\left(S^{I}\right)>$ $V^{R}\left(S^{D}\right) \geq R L$ implying that the bank was fully-hedged. Hence (A.2) implies $R^{b}=R$.
} 
Next, consider the possibility that the equilibrium interest rate is such that $R^{a} \leq\left(F / S^{I}\right)[(1-q) R+\delta+q \omega]$. It is easy to establish that in such circumstances, full-hedging and defaulting in both states are not feasible strategies. ${ }^{10}$ Even if feasible, strategy 2 implies $V<0$. If $R^{a}<\left(F / S^{I}\right)[(1-q) R+\delta+q \omega]$ strategy 3 implies $V<0$.

Hence, the only possible equilibrium interest rate is $R^{a}=\left(F / S^{I}\right)[(1-q) R+$ $\delta+q \omega]$ with banks following strategy 3 . Conditional on strategy 3 , to minimize its expected cost of borrowing, it is optimal for a bank to minimize $V^{R}\left(S^{D}\right)$ subject to the constraint that $V^{R}\left(S^{D}\right) \geq \omega L$. Since $\partial V^{R}\left(S^{D}\right) / \partial x>0$, the bank will choose the lowest $x$ consistent with $V^{R}\left(S^{D}\right) \geq \omega L, x=\left(\omega+\delta-R^{a} S^{I} / S^{D}\right) L /(1-$ q) $\left(1 / S^{I}-1 / S^{D}\right)$, implying $V^{R}\left(S^{D}\right)=\omega L, V^{R}\left(S^{I}\right)=R L, E C B=(1-q) R L+q \omega L$ and $V=0$.

\section{A.2. Firm's Hedging Strategies}

Firm profits, in dollar terms, are given by

$$
\pi_{f}=A h-w h-\left(R^{a}-1\right) d / S+x_{f}(1 / F-1 / S)
$$

where $h$ is the firm's demand for labor, $w$ is the real wage rate, $d$ is the number of pesos borrowed by the firm from the bank, and $x_{f}$ is the number of pesos sold forward by the firm.

Firms maximize $E\left(\pi_{f}\right)=A h-w h-\left(R^{a}-1\right) d / F$ subject to the constraint that they have sufficient pesos on hand to pay their wage bill in advance: $S w h \leq$ $d+S x_{f}(1 / F-1 / S)$, for all $S$. The two constraints imply that $d=x_{f}=F w h$. So $E\left(\pi_{f}\right)=A h-R^{a} w h$. The firm's first order condition for labor is $A=R^{a} w$. Realized profits are given by $\pi_{f}=A h(1-F / S)$ with $E\left(\pi_{f}\right)=0$.

\footnotetext{
${ }^{10}$ Full-hedging is not feasible since $E\left(V^{R}\right)<R L$. For $V^{R}\left(S^{D}\right)-\omega L \geq R L$ the lending condition for strategy 4 can be written as $E\left(V^{R}\right)-\omega L \geq R L$, which would imply that the bank was full hedged. For $V^{R}\left(S^{D}\right)-\omega L<R L$ the condition can be written $V^{R}\left(S^{I}\right)-\omega L \geq R L$. Combining this with (constraint on VRSD) implies $E\left(V^{R}\right) \geq(1-q) R L+\omega L$, which is not true given the condition on $R^{a}$.
} 


\section{A.3. The Lemma and Equations (4.1), (4.7) and (4.8).}

We start by considering the household's optimization problem. The household solves the following dynamic programming problem for $t \geq T+1$ :

$$
V^{F}\left(a_{t}, M_{t}\right)=\max _{c_{t}, a_{t+1}, M_{t+1}}\left[\log c_{t}+\phi \log \frac{M_{t}}{S_{t}}+\beta V^{F}\left(a_{t+1}, M_{t+1}\right)\right]
$$

subject to

$$
a_{t+1}=R a_{t}+w_{t}+\pi_{t}-\tau_{t}-c_{t}-\left(M_{t+1}-M_{t}\right) / S_{t} .
$$

The first order and envelope conditions are: $1 / c_{t}=\theta_{t}$

$$
\begin{gathered}
\beta V_{1}^{F}\left(a_{t+1}, M_{t+1}\right)=\theta_{t} \\
\beta V_{2}^{F}\left(a_{t+1}, M_{t+1}\right)=\theta_{t} / S_{t} \\
V_{1}^{F}\left(a_{t}, M_{t}\right)=\theta_{t} R \\
V_{2}^{F}\left(a_{t}, M_{t}\right)=\phi / M_{t}+\theta_{t} / S_{t},
\end{gathered}
$$

where $\theta_{t}$ is the Lagrange multiplier on the budget constraint.

Substituting (A.6) into (A.6) and noting that $\beta=1 / R$, we have $\theta_{t}=\theta_{t+1}$. This implies that $c_{t}=c_{t+1}=c^{F}$ for $t \geq T+1$. Using this fact and substituting (A.7) into (A.5) we have

$$
\frac{M_{t+1}}{S_{t+1}}=\frac{\beta \phi c^{F}}{S_{t+1} / S_{t}-\beta}, \text { for } t \geq T+1
$$

In period $T$ households face the following dynamic programming problem

$$
V^{D}\left(a_{T}, M_{T}, x_{T}^{h}\right)=\max _{c_{T}, \chi^{D}, a_{T+1}, M_{T+1}}\left[\log c_{T}+\phi \log \frac{M_{T}}{S_{T}}+\beta V^{F}\left(a_{T+1}, M_{T+1}\right)\right]
$$

subject to

$$
a_{T+1}=R a_{T}+w_{T}+\pi_{T}-\tau_{T}-c_{T}-\frac{M_{T+1}-M_{T}}{S_{T}}+\chi^{D}\left(1-\frac{S_{T-1}}{S_{T}}\right)+x_{T}^{h}\left(\frac{1}{F_{T}}-\frac{1}{S_{T}}\right) .
$$

As long as $S_{T}>S_{T-1}$ the household will want to make $\chi^{D}$ infinite if it can. Since it is constrained by the fact that the government will only supply $\chi$ dollars we replace the household's problem with

$$
V^{D}\left(a_{T}, M_{T}, x_{T}^{h}\right)=\max _{c_{T}, a_{T+1}, M_{T+1}}\left[\log c_{T}+\phi \log \frac{M_{T}}{S_{T}}+\beta V^{F}\left(a_{T+1}, M_{T+1}\right)\right]
$$


subject to

$$
a_{T+1}=R a_{T}+w_{T}+\pi_{T}-\tau_{T}-c_{T}-\frac{M_{T+1}-M_{T}}{S_{T}}+\chi\left(1-\frac{S_{T-1}}{S_{T}}\right)+x_{T}^{h}\left(\frac{1}{F_{T}}-\frac{1}{S_{T}}\right) .
$$

The first order and envelope conditions are

$$
\begin{gathered}
c_{T}^{-1}=\theta_{T} \\
\beta V_{1}^{F}\left(a_{T+1}, M_{T+1}\right)=\theta_{T} \\
\beta V_{2}^{F}\left(a_{T+1}, M_{T+1}\right)=\theta_{T} / S_{T} \\
V_{1}^{D}\left(a_{T}, M_{T}, x_{T}^{h}\right)=R \theta_{T} \\
V_{2}^{D}\left(a_{T}, M_{T}, x_{T}^{h}\right)=\phi / M_{T}+\theta_{T} / S_{T} \\
V_{3}^{D}\left(a_{T}, M_{T}, x_{T}^{h}\right)=\theta_{T}\left(1 / F_{T}-1 / S_{T}\right) .
\end{gathered}
$$

Notice that (A.6) implies that $V_{1}^{F}\left(a_{T+1}, M_{T+1}\right)=R / c^{F}$. Since $\beta=1 / R$ combining (A.10) and (A.11) we then obtain $c_{T}=c^{F}$. ¿From (A.7) we have $V_{2}^{F}\left(a_{T+1}, M_{T+1}\right)=$ $\phi / M_{T+1}+1 /\left(c^{F} S_{T+1}\right)$. Hence from (A.12) we have

$$
\frac{M_{T+1}}{S_{T+1}}=\frac{\beta \phi c^{F}}{S_{T+1} / S_{T}-\beta} .
$$

To solve for $c^{F}$ we iterate on (A.3) and combine it with (A.9) to obtain

$$
\begin{gathered}
a_{T}=R^{-1} \sum_{j=0}^{\infty} R^{-j}\left(c_{T+j}-w_{T+j}-\pi_{T+j}+\tau_{T+j}\right)+R^{-1} \sum_{j=0}^{\infty} R^{-j} \frac{M_{T+1+j}-M_{T+j}}{S_{T+j}}- \\
R^{-1}\left[\chi\left(1-S_{T-1} / S_{T}\right)+x_{T}^{h}\left(1 / F_{T}-1 / S_{T}\right)\right] .
\end{gathered}
$$

where we have imposed $\lim _{j \rightarrow \infty} R^{-j} a_{t+j}=0$. Using $c_{t}=c^{F}$, for $t \geq T,(\mathrm{~A} .8)$ and (A.16):

$$
\begin{gathered}
a_{T}=(1+\beta \phi) c^{F} /(R-1)-R^{-1} \sum_{j=0}^{\infty} R^{-j}\left(w_{T+j}+\pi_{T+j}-\tau_{T+j}\right)-R^{-1} M_{T} / S_{T}- \\
R^{-1}\left[\chi\left(1-S_{T-1} / S_{T}\right)+x_{T}^{h}\left(1 / F_{T}-1 / S_{T}\right)\right]
\end{gathered}
$$


For $t<T$, households solve the following dynamic programming problem

$$
\begin{aligned}
V^{I}\left(a_{t}, M_{t}, x_{t}^{h}\right)= & \max _{c_{t}, a_{t+1}, M_{t+1}, x_{t+1}^{h}}\left\{\log c_{t}+\phi \log \left(M_{t} / S_{t}\right)+\right. \\
& \left.\quad \beta\left[(1-q) V^{I}\left(a_{t+1}, M_{t+1}, x_{t+1}^{h}\right)+q V^{D}\left(a_{t+1}, M_{t+1}, x_{t+1}^{h}\right)\right]\right\}
\end{aligned}
$$

subject to

$$
a_{t+1}=R a_{t}+w_{t}+\pi_{t}-\tau-c_{t}-\left(M_{t+1}-M_{t}\right) / S_{t}+x_{t}^{h}\left(1 / F_{t}-1 / S_{t}\right) .
$$

The first order and envelope conditions are

$$
\begin{gathered}
1 / c_{t}=\theta_{t} \\
\beta(1-q) V_{1}^{I}\left(a_{t+1}, M_{t+1}, x_{t+1}^{h}\right)+\beta q V_{1}^{D}\left(a_{t+1}, M_{t+1}, x_{t+1}^{h}\right)=\theta_{t} \\
\beta(1-q) V_{2}^{I}\left(a_{t+1}, M_{t+1}, x_{t+1}^{h}\right)+\beta q V_{2}^{D}\left(a_{t+1}, M_{t+1}, x_{t+1}^{h}\right)=\theta_{t} / S_{t} \\
(1-q) V_{3}^{I}\left(a_{t+1}, M_{t+1}, x_{t+1}^{h}\right)+q V_{3}^{D}\left(a_{t+1}, M_{t+1}, x_{t+1}^{h}\right)=0 \\
V_{1}^{I}\left(a_{t}, M_{t}, x_{t}^{h}\right)=\theta_{t} R \\
V_{2}^{I}\left(a_{t}, M_{t}, x_{t}^{h}\right)=\phi / M_{t}+\theta_{t} / S_{t} \\
V_{3}^{I}\left(a_{t}, M_{t}, x_{t}^{h}\right)=\theta_{t}\left(1 / F_{t}-1 / S_{t}\right) .
\end{gathered}
$$

If we substitute (A.15) and (A.26) into (A.23) we obtain

$$
(1-q) \theta_{t+1}^{I}\left(1 / F_{t+1}^{I}-1 / S_{t+1}^{I}\right)+q \theta_{t+1}^{D}\left(1 / F_{t+1}^{D}-1 / S_{t+1}^{D}\right)=0 .
$$

Here $F_{t+1}^{I}, S_{t+1}^{I}$ and $\theta_{t+1}^{I}$ represent the values taken on by $F_{t+1}, S_{t+1}$ and $\theta_{t+1}$ if the exchange rate remains fixed at $t+1$, while $F_{t+1}^{D}, S_{t+1}^{D}$ and $\theta_{t+1}^{D}$ represent the values taken on by $F_{t+1}, S_{t+1}$ and $\theta_{t+1}$ if a devaluation occurs at date $t+1$. Since $F_{t+1}$ is realized prior to $S_{t+1}$, it follows that $1 / F_{t+1}^{D}=1 / F_{t+1}^{I}=1 / F_{t+1}=$ $(1-q) / S_{t+1}^{I}+q / S_{t+1}^{D}$. Using this result (A.27) implies $\theta_{t+1}^{D}=\theta_{t+1}^{I}=\theta_{t+1}$. From (A.20) and (A.10) this implies that the value of $c_{t+1}=1 / \theta_{t+1}$ does not depend on whether a devaluation occurs or not at $t+1$.

Notice that (A.13) implies $V_{1}^{D}\left(a_{t+1}, M_{t+1}, x_{t+1}^{h}\right)=R / c_{t+1}$. Substituting this, (A.20) and (A.24) into (A.21) we get $c_{t}=c$ for all $t$. Next we substitute (A.14), (A.25), (A.10), (A.20), and our previous results into (A.22) to get

$$
M_{t+1}=\frac{\beta \phi c}{\left(\frac{1}{S_{t}}-\beta \frac{1}{F_{t+1}}\right)}, \text { for } t<T
$$


To solve for the equilibrium sequences of $S_{t}$ we note that the government uses the money supply rule $M_{t}=M^{I}$ for $t \leq T$, and $M_{T+j}=\gamma^{j}\left(M_{T}-\chi S_{T-1}\right)$ for $j \geq 1$. From (A.8) and (A.16) we have $S_{t}^{-1}=\beta S_{t+1}^{-1}+\beta \phi c^{F} M_{t+1}^{-1}$ for $t \geq T$. Iterating forward on this equation, using the money supply rule, and imposing $\lim _{j \rightarrow \infty} \beta^{j} S_{t+j}^{-1}=0,{ }^{11}$ we obtain $S_{T+j}=\gamma^{j} S_{T}$ for $j \geq 0$, and $S_{T}=R(\gamma-\beta)\left(M^{I}-\right.$ $\left.\chi S_{T-1}\right) / \phi c$. From (A.28) we have $S_{t}=S^{I}$ for $t<T$, and $S_{T}=S^{D}$ where $S^{D}=R(\gamma-\beta)\left(M^{I}-\chi S^{I}\right) / \phi c$ and $S^{I}=R[1-\beta(1-q)] /\left(\phi c / M^{I}+q / S^{D}\right)$. Thus, given $M^{D}=M^{I}-\chi S^{I}$, we have $M^{D} / S^{D}=\phi c /(R \gamma-1)$. We have proven the Lemma.

We note that in equilibrium

$$
w_{t}=\left\{\begin{array}{ll}
w^{I} & \text { for } t \leq T \\
w^{F} & \text { for } t>T
\end{array} \quad \pi_{t}=\left\{\begin{array}{ll}
\pi^{I} & \text { for } t<T \\
\pi^{D} & \text { for } t=T \\
0 & \text { for } t>T
\end{array} \quad \tau_{t}= \begin{cases}\tau & \text { for } t \neq T \\
\tau+\tau^{D} & \text { for } t=T\end{cases}\right.\right.
$$

Since the household does not know when the devaluation will take place, in every period $t$ in which the devaluation has not yet taken place, the household will set $x_{t+1}^{h}$ and $a_{t+1}$ so that (A.18) holds for $t+1$ rather than $T$. This implies that for all $t \leq T$,

$$
x_{t}^{h}=\frac{-R a_{t}+\frac{R+\phi}{R-1} c-\left(w^{I}+\frac{1}{R-1} w^{F}\right)-\pi^{D}+\frac{R}{R-1} \tau+\tau^{D}-\frac{M^{I}}{S^{D}}-\chi\left(1-\frac{S^{I}}{S^{D}}\right)}{\left(\frac{1}{F}-\frac{1}{S^{D}}\right)}
$$

Substituting this into (A.19) we get $a_{t}=\left(R a_{t-1}-\kappa\right) /(1-q), t \leq T$, where

$$
\begin{gathered}
\kappa=\left(1-q+q \frac{R+\phi}{R-1}\right) c+\left[(R-1+q) \frac{\tau}{R-1}+q \tau^{D}\right]-\left(w^{I}+\frac{q}{R-1} w^{F}\right)- \\
{\left[(1-q) \pi^{I}+q \pi^{D}\right]+q\left[\frac{M^{I}}{S^{D}}+\chi\left(1-\frac{S^{I}}{S^{D}}\right)\right] .}
\end{gathered}
$$

If we use (A.3) to obtain the household's lifetime budget constraint at any $t>T$ we have $a_{t}=a^{F}$ where

$$
a^{F}=\frac{(R+\phi) \gamma-(1+\phi)}{(R-1)(R \gamma-1)} c+\frac{1}{R-1}\left(\tau-w^{F}\right) .
$$

\footnotetext{
${ }^{11}$ This condition is implied by the transversality condition applying to real balances.
} 
Hence, under the fixed exchange rate regime, once the agent has set $a_{t+1}$, this implies that $E_{t} a_{t+j}=R^{j-1} a_{t+1}+\left(1+R+\cdots+R^{j-2}\right)\left(q a^{F}-\kappa\right)$ for $j \geq 2$. If we impose $\lim _{j \rightarrow \infty} E_{t} R^{-j} a_{t+j}=0$ we get $a_{t}=a^{I}=\left(\kappa-q a^{F}\right) /(R-1)$ for $t \leq T$. Given the law of motion above, this implies $a^{I}=a^{F}=a_{0}=\kappa /(R-1+q)$. Furthermore $x_{t}^{h}=x^{h}$ for $t \leq T$, where $x^{h}$ is obtained by subsitituting $a_{t}=a_{0}$ into (A.29).

The government's flow budget constraint for $t \neq T$ is $f_{t+1}=R f_{t}+\left(M_{t+1}\right.$ $\left.M_{t}\right) / S_{t}+\tau_{t}-g_{t}$. For $t=T$, the government budget constraint is

$$
f_{T+1}=R f_{T}+\left(M_{T+1}-M_{T}\right) / S_{T}-\chi\left(1-S_{T-1} / S_{T}\right)-\Gamma+\tau_{T}-g_{T} .
$$

This implies that the government's lifetime budget constraint at date $T$ is

$$
f_{T}=R^{-1}\left[\chi\left(1-\frac{S_{T-1}}{S_{T}}\right)+\Gamma+\sum_{j=0}^{\infty} R^{-j}\left(g_{T+j}-\tau_{T+j}\right)-\sum_{j=0}^{\infty} R^{-j} \frac{M_{T+1+j}-M_{T+j}}{S_{T+j}}\right] .
$$

If we combine this with (A.17) we get

$$
a_{T}+f_{T}=R^{-1}\left[\sum_{j=0}^{\infty} R^{-j}\left(c_{T+j}+g_{T+j}-w_{T+j}-\pi_{T+j}\right)+\Gamma-x_{T}^{h}\left(\frac{1}{F_{T}}-\frac{1}{S_{T}}\right)\right] .
$$

We assume that $f_{t}=f_{0}=(g-\tau) /(R-1)$, for $t \leq T$, and that $g_{t}=g, \forall t$. We also use the facts that $a_{T}=a_{0}, c_{t}=c, \forall t, 1 / F_{T}=1 / F=(1-q) / S^{I}+q / S^{D}, S_{T}=S^{D}$ and $x_{T}^{h}=x^{h}$, as well as the sequences for $w_{t}$ and $\pi_{t}$ given above to obtain

$$
a_{0}+f_{0}=\frac{1}{R-1}(c+g)-R^{-1}\left[w^{I}+\frac{1}{R-1} w^{F}+\pi^{D}-\Gamma+x^{h}\left(\frac{1}{F}-\frac{1}{S^{D}}\right)\right] .
$$

Since $\tau_{t}=\tau=g-(R-1) f_{0}$, for $t<T$, (A.19) implies

$$
a_{0}+f_{0}=\frac{1}{R-1}(c+g)-\frac{1}{R-1}\left[w^{I}+\pi^{I}+x^{h}\left(\frac{1}{F}-\frac{1}{S^{I}}\right)\right] .
$$

Combining these two equations we have

$$
x^{h}=\left[w^{I}-w^{F}+R \pi^{I}-(R-1) \pi^{D}+(R-1) \Gamma\right] /\left[(R-1+q)\left(\frac{1}{S^{I}}-\frac{1}{S^{D}}\right)\right],
$$


which is equivalent to (A.29).

Substituting (A.32) into (A.31) and noting that $(1-q) \pi^{I}+q \pi^{D}=0$, we get

$$
c=(R-1)\left(a_{0}+f_{0}\right)-g+(R-1+q)^{-1}\left[(R-1) w^{I}+q w^{F}-q(R-1) \Gamma\right],
$$

which establishes (4.1). The expressions for $S^{D}$ and $S^{I}$ given above can be rewritten as

$$
\begin{aligned}
m^{I} & =\frac{\phi c}{R \gamma-1} \frac{S^{D}}{S^{I}}+\chi \\
m^{I} & =\frac{\phi c}{R-1+q\left(1-S^{I} / S^{D}\right)},
\end{aligned}
$$

where $m^{I}=M^{I} / S^{I}$, and which establishes (4.8). Notice that our previous assumptions, (A.8) and (A.16) imply that (A.30) can be rewritten as

$$
\tau^{D}+\frac{R}{R-1} \frac{\gamma-1}{R \gamma-1} \phi c=\chi+\Gamma .
$$

\section{A.4. Proofs of Propositions 3-5}

We first provide some intuition for the propositions. To do this assume that there exists a solution $\left(c, m^{I}, S^{I} / S^{D}, \gamma\right)$ to equations (A.33)-(A.36), with $c>0$ and $\gamma \geq 1$. Given $c$ and $\gamma$, we can plot $m^{I}$ as a function of $S^{I} / S^{D}$ using (A.35) and

$$
m^{I}=\left[\frac{S^{D}}{S^{I}}+\frac{R}{R-1}(\gamma-1)\right] \frac{\phi c}{R \gamma-1}+\tau^{D}-\Gamma,
$$

which is the result of substituting (A.36) into (A.34). We do this in Figure 1. Equation (A.35) defines a curve with an intercept at $\phi c /(R-1+q)$, which is increasing, equals $\phi c /(R-1)$ at $S^{I} / S^{D}=1$ and has a vertical asymptote at $1+(R-1) / q$. Equation (A.37) defines a curve which is decreasing, with a vertical asymptote at 0 , equal to $\phi c /(R-1)+\tau^{D}-\Gamma$ at $S^{I} / S^{D}$, and with a horizontal asymptote at $m^{I}=\chi$, as $S^{I} / S^{D} \rightarrow \infty$. It is clear from Figure 1 that when there are guarantees, so that $\Gamma>0$, the equilibrium value of $S^{I} / S^{D}<1$ as long as $\tau^{D}<\Gamma$, as in Propositions 3 and 4 . However, in the absence of guarantees, $\Gamma=0$, and with no fiscal reform, $\tau^{D}=0, S^{I} / S^{D}=1$ as in Proposition 5 . We now establish that in each case there are solutions with $c>0$ and $\gamma \geq 1$. 
Proposition 4. We prove Proposition 4 first as we can take the post-devaluation money growth rate, $\gamma>1$, parametrically. Consider the four equations (A.33)(A.36). Let $\sigma=S^{I} / S^{D}$. In the model with guarantees $w^{I}=A(1-q+q \sigma) /[(1-$ q) $R+\delta+q \omega]$ and $w^{F}=A /[\gamma(R+\delta)]$. When there are government guarantees, banks will go bankrupt in the devaluation state and the government will pay $\Gamma=R L=R\left(d / S^{I}\right)=R F w^{I} / S^{I}$ to the banks' foreign creditors. Hence, we define the function $\Gamma(q)=R A /[(1-q) R+\delta+q \omega]$ for $q>0$, and $\Gamma(q)=0$ for $q=0$. For convenience, we define the function $\bar{\Gamma}(q)=R A /[(1-q) R+\delta+q \omega]$ for $0 \leq q \leq 1$, so that $\bar{\Gamma}(0)=\lim _{0 \leftarrow q} \Gamma(q)$. This definition is useful because it equates the function at $q=0$ to its limit as $q$ approaches 0 from above. I.e. $\bar{\Gamma}(0)=\lim _{0 \leftarrow q} \bar{\Gamma}(q)$ whereas $\Gamma(0) \neq \lim _{0 \leftarrow q} \Gamma(q)$.

We rewrite $(\mathrm{A} .33)$ as $c=c^{1}(\sigma ; q)$ where $c^{1}(\sigma ; q) \equiv(R-1)\left(a_{0}+f_{0}\right)-g+\frac{A}{R-1+q}\left[(R-1) \frac{1-q+q \sigma-q R}{(1-q) R+\delta+q \omega}+\frac{q}{\gamma(R+\delta)}\right]$

Combining (A.35) and (A.34) we get $c=c^{2}(\sigma ; q)$, where

$$
c^{2}(\sigma ; q) \equiv(\chi / \phi)\left[\frac{1}{R-1+q(1-\sigma)}-\frac{1}{(R \gamma-1) \sigma}\right]^{-1} .
$$

Given a solution for $c$ and $\sigma$ the required fiscal reform is obtained from (A.36) as

$$
\tau^{D}=\chi+\Gamma(q)-\frac{R}{R-1} \frac{\gamma-1}{R \gamma-1} \phi c
$$

To show that there is an equilibrium with self-fulfilling attacks, we will demonstrate that $c^{1}(\sigma ; q)=c^{2}(\sigma ; q)>0$ for some $\sigma<1$ and $q>0$. To do this we make reference to Figure 2.

The first step in our proof is to characterize the curves $c^{1}(\sigma ; q)$ and $c^{2}(\sigma ; q)$. The straight line is $c^{1}(\sigma ; q)$. It is clear from (A.38) that $c_{\sigma}^{1}(\sigma ; q)>0$ for $q>0$. We have $\lim _{q \rightarrow 0} c^{1}(\sigma ; q)=c_{S}, \forall \sigma$, where $c_{S}$ is the level of consumption under the sustainable fixed exchange rate regime. For $\sigma \leq 1$

$$
\frac{1-q+q \sigma-q R}{(1-q) R+\delta+q \omega}<\frac{1}{R+\delta} \text { and } \frac{1}{\gamma(R+\delta)}<\frac{1}{R+\delta}
$$

It follows that $c^{1}(\sigma ; q)<c_{S}$ for all $q>0$. Furthermore it is straightforward to show that $c_{q}^{1}(\sigma ; q)<0$ for all $\sigma$. 
The curve in Figure 2 is $c^{2}(\sigma ; q)$. We note that $c^{2}(\sigma ; q)>0$ only for $\sigma>\underline{\sigma}(q)=$ $(R-1+q) /(R \gamma-1+q)$. For $\sigma>\underline{\sigma}(q), c_{\sigma}^{2}(\sigma ; q)<0$, and $\lim _{\underline{\underline{\sigma}}(q) \leftarrow \sigma} c^{2}(\sigma ; q)=\infty$. Also $c^{2}(1 ; q)=c^{2}(1)=(\chi / \phi)(R-1)(R \gamma-1) /[R(\gamma-1)]>0$. We have

$$
\lim _{q \rightarrow 0} c^{2}(\sigma ; q)=(\chi / \phi)\left[\frac{1}{R-1}-\frac{1}{(R \gamma-1) \sigma}\right]^{-1}<c^{2}(\sigma ; q)
$$

for $\underline{\sigma}(0)<\underline{\sigma}(q)<\sigma<1$. We also note that it is straightforward to show that $c_{q}^{2}(\sigma ; q)>0$ for $\sigma<1$, while $c_{q}^{2}(\sigma ; q)=0$ for $\sigma=1$.

Now that we have characterized $c^{1}$ and $c^{2}$ we conclude our proof. For fixed $q$, Figure 2 makes clear that a necessary and sufficient condition for a solution such that $c>0$ and $\sigma<1$ is

$$
c^{1}(1 ; q)>c^{2}(1)>0 .
$$

Since $\lim _{0 \leftarrow q} c^{1}(1, q)=c_{S}$, (A.41) will be satisfied for sufficiently small $q$ as long as $c_{S}>c^{2}(1)$ or, equivalently, as stated in the proposition, if $\chi<R(\gamma-1) m_{S} /(R \gamma-$ 1 ), where $m_{S}=\phi c_{S} /(R-1)$ is the level of real balances under the sustainable fixed exchange rate regime.

Notice that since $c<c_{S}$ and $\chi<R(\gamma-1) m_{S} /(R \gamma-1)$, (A.40) implies that $\tau^{D}<\Gamma(q)$ in equilibrium.

Proposition 3. We rewrite (A.33)-(A.36) as $c=c^{1}(\gamma, \sigma ; q)$, where

$$
\begin{gathered}
c^{1}(\gamma, \sigma ; q) \equiv(R-1)\left(a_{0}+f_{0}\right)-g+\frac{A}{R-1+q}\left[(R-1) \frac{1-q+q \sigma-q R}{(1-q) R+\delta+q \omega}+\frac{q}{\gamma(R+\delta)}\right] \\
c=c^{2}(\gamma, \sigma ; q) \equiv(\chi / \phi)\left[\frac{1}{R-1+q(1-\sigma)}-\frac{1}{(R \gamma-1) \sigma}\right]^{-1} \\
c=c^{3}(\gamma ; q)=\frac{1}{\phi} \frac{R-1}{R} \frac{R \gamma-1}{\gamma-1}[\chi+\bar{\Gamma}(q)] .
\end{gathered}
$$

The additional complication of this proposition is that we now have 3 nonlinear equations in 3 unknowns, the additional unknown being $\gamma$. Our proof is structured as follows. First, we borrow the analysis from the proof of Proposition 4 to solve the equation $c^{1}(\gamma, \sigma ; q)=c^{2}(\gamma, \sigma ; q)$ for $(c, \sigma)$ given $(\gamma ; q)$. We will denote the implied solution for $c$ as $C^{1}(\gamma ; q)$. This is symmetric to the second part of our proof which examines $c^{3}(\gamma ; q)$. During these two steps we characterize $C^{1}$ and $c^{3}$ 
using Figure 3. Our proof concludes by showing that there are pairs $(\gamma ; q)$ with $\gamma>1$, and $0<q<1$, such that $C^{1}(\gamma ; q)=c^{3}(\gamma ; q)$.

Step 1. Taking $\gamma$ as given, we denote the value of $\sigma$ for which $c^{1}(\gamma, \sigma ; q)=$ $c^{2}(\gamma, \sigma ; q)$ as $\sigma=\sigma(\gamma ; q)$. The value of $c$ for which $c^{1}(\gamma, \sigma ; q)=c^{2}(\gamma, \sigma ; q)$ is given by. $c=C^{1}(\gamma ; q)=c^{1}(\gamma, \sigma(\gamma ; q) ; q)=c^{2}(\gamma, \sigma(\gamma ; q) ; q)$.

It is useful to characterize $\sigma$ and $C^{1}$. First, we examine their derivatives with respect to $q$. Recall, from Proposition 4, that $c_{q}^{1}<0$, for all $0 \leq \sigma \leq 1$. Furthermore, $c_{q}^{2}>0$ for $\sigma<1$, while $c_{q}^{2}=0$ for $\sigma=1$. We also have $c_{\sigma}^{1}=0$ for $q=0, c_{\sigma}^{1}>0$ for $q>0$ and $c_{\sigma}^{2}<0$ for all $q$. By totally differentiating $c^{1}=c^{2}$ with respect to $\sigma$ and $q$, we can use these facts to show that $\sigma_{q}=\left(c_{q}^{2}-c_{q}^{1}\right) /\left(c_{\sigma}^{1}-c_{\sigma}^{2}\right)>0$. We cannot unambiguously sign $C_{q}^{1}=c_{q}^{1}+c_{\sigma}^{1} \sigma_{q}=\left(c_{q}^{1} c_{\sigma}^{2}-c_{\sigma}^{1} c_{q}^{2}\right) /\left(c_{\sigma}^{2}-c_{\sigma}^{1}\right)$. Over some range, however, $C^{1}$ must be decreasing in $q$ because $C^{1}=c_{S}$ for $q=0$, $C^{1}<c_{S}$ for all $q>0$, and $\left.C_{q}^{1}\right|_{q=0}=\left.c_{q}^{1}\right|_{q=0}<0$.

Second, we characterize the range of $q$ for which $\sigma$ and $C^{1}$ are defined. Recall from the proof of Proposition 4, that (i) $c^{2}(\gamma, 1 ; q)$ does not depend on $q$ so we denote it as $c^{2}(\gamma, 1)$ and (ii) $\sigma$ and $C^{1}$ are defined for any $q$ such that $c^{1}(\gamma, 1 ; q)>$ $c^{2}(\gamma, 1)$. There are two possibilities implied by these facts: $\sigma$ and $C^{1}$ are defined either (i) for all $0 \leq q \leq \bar{q}(\gamma)=1$, or (ii) for all $0 \leq q<\bar{q}(\gamma)<1$ where $\vec{q}(\gamma)$ is the value of $q$ for which $c^{1}(\gamma, 1 ; q)=c^{2}(\gamma, 1)$. In the latter case, when $\bar{q}(\gamma)<1$, we also have the result that the lowest value of $C^{1}$ for that $\gamma$ is $c^{2}(\gamma, 1)$.

Third, we characterize the derivatives of $\sigma$ and $C^{1}$ with respect to $\gamma$. From (A.42), $c_{\gamma}^{1}=0$ for $q=0$ and $c_{\gamma}^{1}<0$ for $q>0$. From (A.43), $c_{\gamma}^{2}<0$ for all $q$. Hence, it is not possible to sign $\sigma_{\gamma}=\left(c_{\gamma}^{2}-c_{\gamma}^{1}\right) /\left(c_{\sigma}^{1}-c_{\sigma}^{2}\right)$. However, it is possible to sign $C_{\gamma}^{1}$ since $C_{\gamma}^{1}=c_{\gamma}^{1}+c_{\sigma}^{1} \sigma_{\gamma}=\left(c_{\gamma}^{1} c_{\sigma}^{2}-c_{\sigma}^{1} c_{\gamma}^{2}\right) /\left(c_{\sigma}^{2}-c_{\sigma}^{1}\right)$. This implies $C_{\gamma}^{1}=0$ for $q=0$ and $C_{\gamma}^{1}<0$ for $q>0$.

Finally, we characterize the range of $\gamma$ for which $\sigma$ and $C^{1}$ are defined. The lower bound on values of $\gamma$ for which $\sigma$ and $C^{1}$ are defined is

$$
\underline{\gamma}=\frac{R c_{S}-(\chi / \phi)(R-1)}{R\left[c_{S}-(\chi / \phi)(R-1)\right]}
$$

because $c^{2}(\underline{\gamma}, 1)=c_{S}$. Hence $\bar{q}(\underline{\gamma})=0$. For $\gamma>\underline{\gamma}, 0<(R-1) \chi / \phi<c^{2}(\gamma, 1)<c_{S}$. This implies that there is no upper limit on $\gamma$ for which $\sigma$ and $C^{1}$ are defined, since $\lim _{0 \leftarrow q} c^{1}(\gamma, 1 ; q)=c_{S}>c^{2}(\gamma, 1)$ for all $\gamma>\underline{\gamma}$. So we have $\bar{q}(\gamma)>0$ for all $\gamma>\underline{\gamma}$. 
$C^{1}$ is illustrated as a function of $q$ in Figure 3 using these results. Notice that $C^{1}(\underline{\gamma} ; q)$ is only defined at $q=0$ and equals $c_{S}$. For any $\gamma>\underline{\gamma}$, such as $\gamma^{*}, C^{\overline{1}}(\gamma ; q)=c_{S}$ for $q=0$, and $C^{1}(\gamma ; q)<c_{S}$ for $0<q<\bar{q}(\gamma)$. The figure is consistent with $C_{\gamma}^{1}<0$, but since we cannot $\operatorname{sign} C_{q}^{1}$, we illustrate $C^{1}$ as a non-monotonic function of $q$, except in the neighborhood of $q=0$ since $\left.C_{q}^{1}(\gamma ; q)\right|_{q=0}=\left.c_{q}^{1}\right|_{q=0}<0$. In drawing the figure we have also used the otherwise unimportant fact that $\left.c_{q q}^{1}\right|_{q=0}<0$.

Step 2. Now consider $c^{3}(\gamma ; q)$. It is defined for all $0 \leq q \leq 1$ and $\gamma>1$. From (A.44), $c_{\gamma}^{3}<0$ and $c_{q}^{3}>0$. Given the assumption in the statement of the proposition that $\phi c_{S} /(R-1)<\chi+\Gamma(q)$ for some $q>0$, it follows that $\phi c_{S} /(R-1)<\chi+\bar{\Gamma}(0)$. Hence, we can evaluate $c^{3}$ at

$$
\gamma^{*}=\frac{R \phi c_{S}-(R-1)[\chi+\bar{\Gamma}(0)]}{R \phi c_{S}-R(R-1)[\chi+\bar{\Gamma}(0)]}>\underline{\gamma}>1
$$

We get $c^{3}\left(\gamma^{*} ; q\right)=c_{S}[\chi+\bar{\Gamma}(q)] /[\chi+\bar{\Gamma}(0)]$. This implies $c^{3}\left(\gamma^{*}, 0\right)=c_{S}$ and that $c^{3}\left(\gamma^{*}, q\right)>c_{S}$ for all $q>0$. For any $\gamma<\gamma^{*}, c^{3}(\gamma, q)>c_{S}$ for all $q$. For any $\gamma>\gamma^{*}$, $c^{3}(\gamma, 0)<c_{S}$.

$c^{3}$ is illustrated as a function of $q$ in Figure 3 using these results. In drawing the figure we have used the otherwise unimportant facts that $c_{q q}^{3}>0$ and $\left.c_{q \gamma}^{3}\right|_{q=0}<0$.

Conclusion. With reference to Figure 3 it is clear that no equilibria exist for $\gamma<\gamma^{*}$. Consider, instead, any $\gamma>\gamma^{*}$. Clearly $c^{3}(\gamma, 0)<C^{1}(\gamma, 0)=c_{S}$. Furthermore, since $c^{3}$ is a continuous, increasing function of $q$, and is defined for all $0 \leq q \leq 1$, and since $C^{1}$ is a continuous function of $q$, a sufficient condition for $C^{1}$ to cross $c^{3}$ at least once for $0<q<1$ is $c^{3}(\gamma, 0) \geq C^{1}(\gamma, \bar{q}(\gamma))$.

Notice that when $\bar{q}(\gamma)<1, C^{1}(\gamma, \bar{q}(\gamma))=c^{2}(\gamma, 1)$ and the sufficient condition for an intersection becomes $c^{3}(\gamma, 0) \geq c^{2}(\gamma, 1)$; some algebra shows that this is equivalent to $\bar{\Gamma}(0) \geq 0$ which always holds. So for any $\gamma>\gamma^{*}$ with $\bar{q}(\gamma)<1$, there is at least one $0<q<1$ for which an equilibrium exists with $c<c_{S}$ and $\sigma<1$.

The only situation that remains for us to consider is the possibility that there are no $\gamma>\gamma^{*}$ for which $\bar{q}(\gamma)<1$. That is $\bar{q}(\gamma)=1$ for all $\gamma>\gamma^{*}$. This implies that $C^{1}(\gamma, \bar{q}(\gamma))=C^{1}(\gamma, 1)=c^{1}(\gamma, \sigma(\gamma, 1) ; 1)$. Notice that $\lim _{\gamma^{*} \leftarrow \gamma} c^{3}(\gamma, 0)=c_{S}$. On the other hand,

$$
\lim _{\gamma^{*} \leftarrow \gamma} c^{1}(\gamma, \sigma(\gamma, 1) ; 1)=c_{S}-A\left[\frac{R \gamma^{*}-1}{R \gamma^{*}(R+\delta)}+\frac{R-1}{R} \frac{R-\sigma\left(\gamma^{*}, 1\right)}{\delta+\omega}\right]<c_{S} .
$$


This implies that the sufficient condition for an intersection is satisfied, at least, for $\gamma$ sufficiently close to $\gamma^{*}$. For these $\gamma$, there is at least one $0<q<1$ for which an equilibrium exists with $c<c_{S}$ and $\sigma<1$.

Proposition 5. We focus, again, on the four equations (A.33)-(A.36). Without guarantees $w^{I}=A(1-q+q \sigma) /(R+\delta), w^{F}=A /[\gamma(R+\delta)]$ and $\Gamma=0$. This means (A.33) becomes

$$
c=(R-1)\left(a_{0}+f_{0}\right)+\frac{A}{(R-1+q)(R+\delta)}[(R-1)(1-q+q \sigma)+q / \gamma]-g,
$$

With $\tau^{D}=0$, and $\Gamma=0,($ A.36) is given by

$$
\frac{R}{R-1} \frac{\gamma-1}{R \gamma-1} \phi c=\chi
$$

Notice that (A.46) combined with (A.35) and (A.34) implies

$$
\left[\frac{R}{R-1}(\gamma-1)+\frac{1}{\sigma}\right] \frac{\phi c}{R \gamma-1}=\frac{\phi c}{R-1+q(1-\sigma)} .
$$

It is easy to verify that for any $c>0,\left(\right.$ A:47) implies $\sigma=1 .{ }^{12}$

\footnotetext{
${ }^{12}$ Since (A.47) is a quadratic equation, there is another solution for $\sigma$, but it is negative.
} 
Figure 1

Diagram for Propositions 3-5

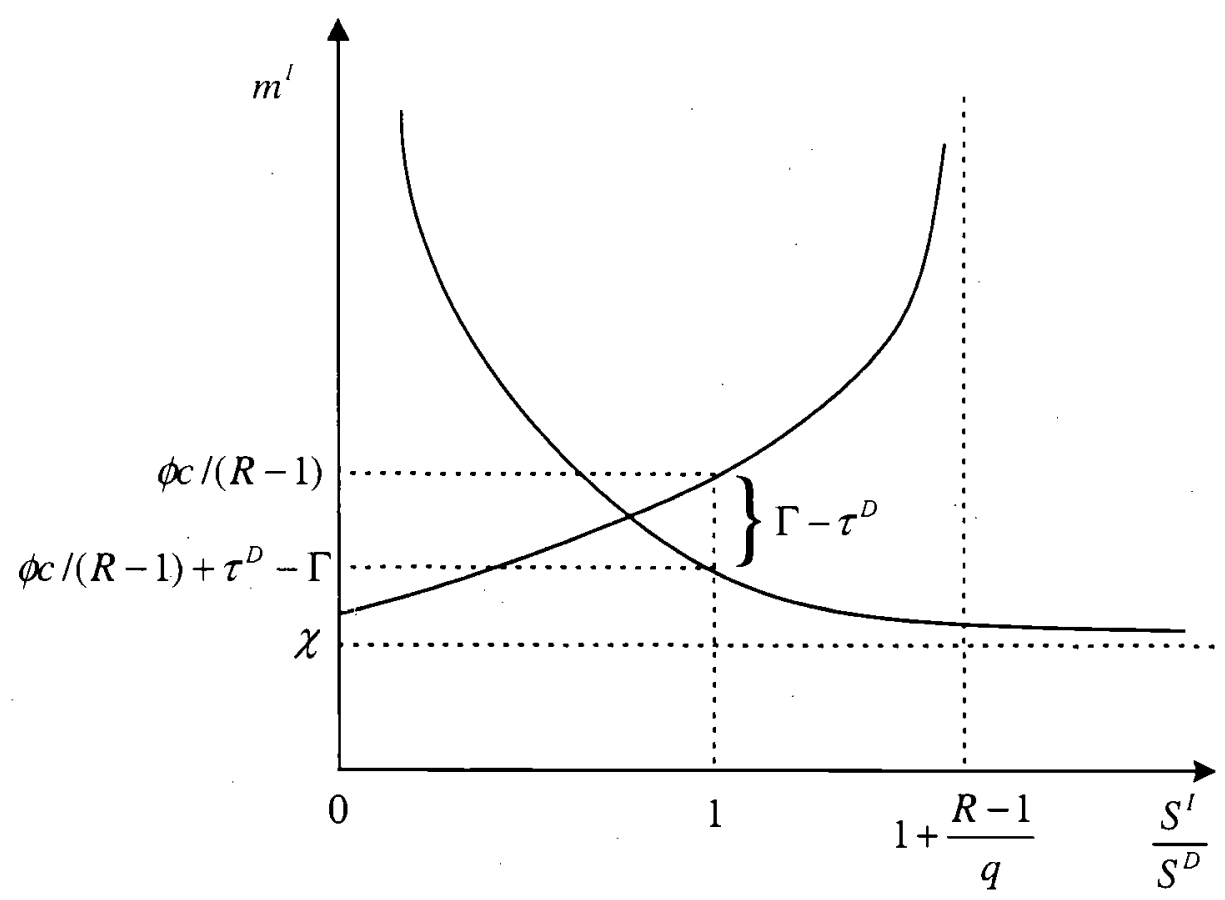


Figure 2

Diagram for Proposition 4

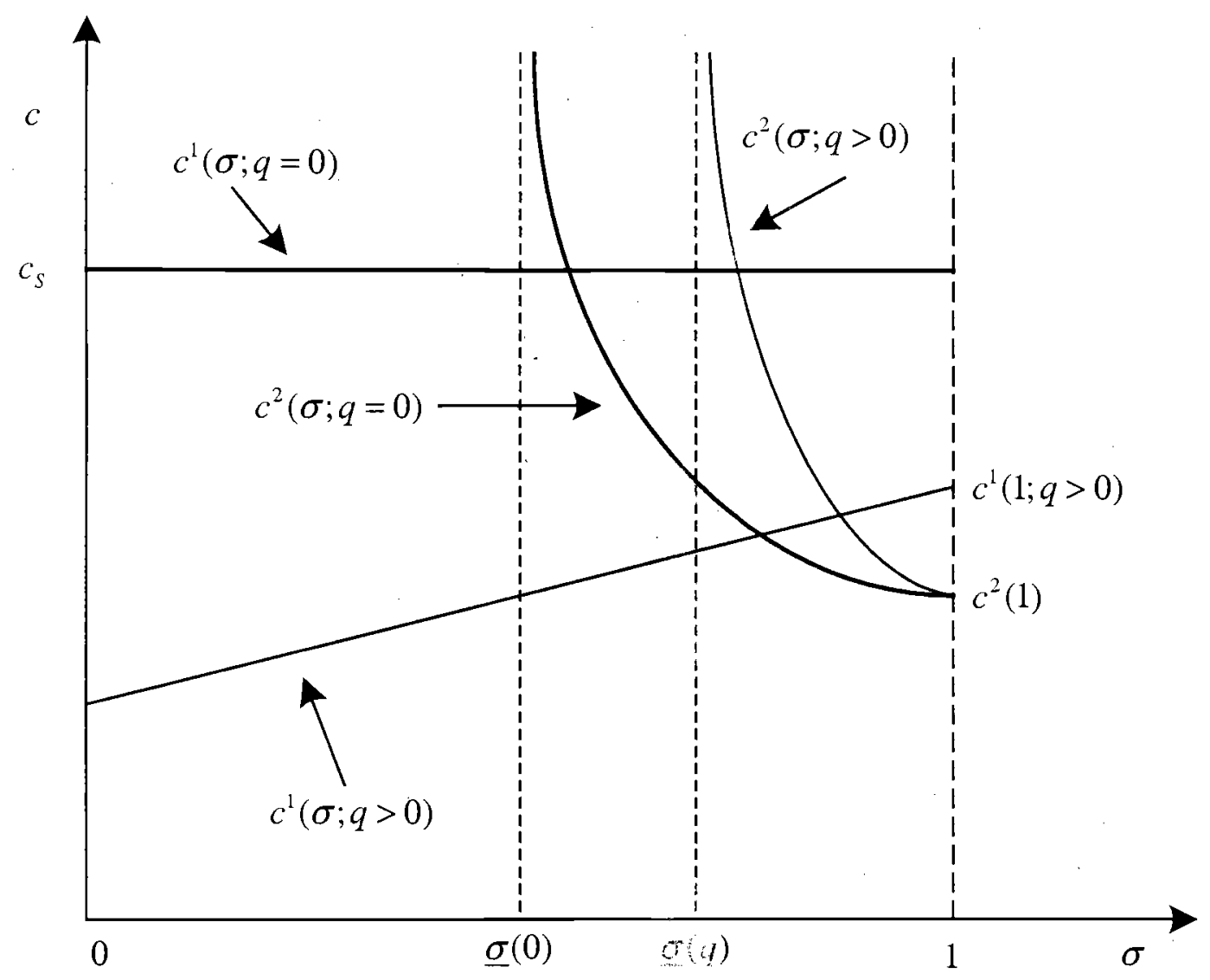


Figure 3

Diagram for Proposition 3

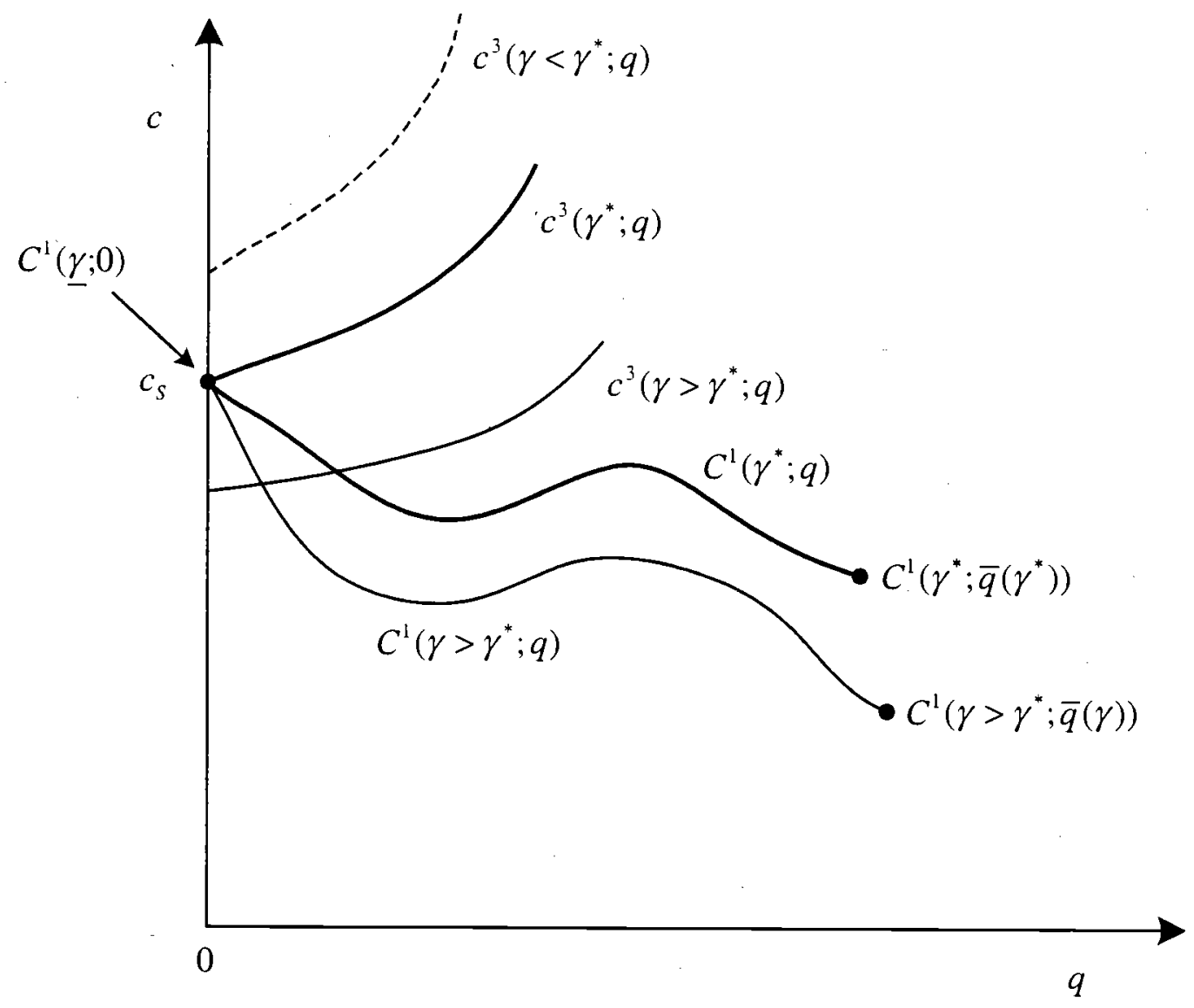

